\title{
Florestas maduras da região metropolitana de São Paulo: diversidade, composição arbórea e variação florística ao longo de um gradiente litoral-interior, Estado de São Paulo, Brasil ${ }^{1}$
}

\author{
Eduardo Hortal Pereira Barretto ${ }^{2,4}$ e Eduardo Luís Martins Catharino ${ }^{3}$
}

Recebido: 23.12.2014; aceito: 30.03 .2015

\begin{abstract}
Mature Atlantic Forest from São Paulo metropolitan area: diversity, arboreal composition, and floristic variation along a littoral-interior gradient, São Paulo State, Brazil). This survey was carried out in order to characterize the tree component of mature Atlantic Forests from São Paulo metropolitan area, São Paulo State, Brazil, to check if there is a floristic variation along the highlands of the region towards littoral-interior, to verify which environmental factors could have influence on it, and to contribute to the classification and conservation of these forests. In order to perform this study, two plots $(20 \times 50 \mathrm{~m})$ were installed on three mature forests located in the cities of São Paulo (Marsilac), Cotia (Morro Grande Forest Reserve), and Itapevi, with samples from all arboreal individuals with circumference at breast height $\mathrm{CBH} \geq 15 \mathrm{~cm}$. Clusters (UPGMA) and ordinations (DCA) analysis were performed between the plots, using species density data. This survey resulted in a sample of 943 trees belonging to 50 families, 109 genera, 184 species; Shannon index 4.62; Pielou equability 0.88 ; basal area $46.1 \mathrm{~m}^{2} \mathrm{ha}^{-1}$, and density of $1.572 \mathrm{ind} \mathrm{ha}^{-1}$. The clusters and ordination analysis indicated that there was greater similarity between Marsilac and Morro Grande, with a tendency to form a more homogeneous floristic block, while Itapevi was isolated from the others. This floristic variation was attributed to the drier winter in Itapevi region, allowing the occurrence of some species usually associated with seasonal semideciduous forests. However, it was verified that the forests of São Paulo metropolitan area are composed of a predominantly ombrophilous flora, with variable presence of semideciduous forest species, mixed, or cold-wet forests. The high diversity of the mature forests, the presence of a large number of rare and threatened species, and the scarcity of these forest remnants, require immediate protection and conservation actions. Keywords: Atlantic forest, biodiversity, climax, conservation, phytogeography
\end{abstract}

RESUMO - (Florestas maduras da região metropolitana de São Paulo: diversidade, composição arbórea e variação florística ao longo de um gradiente litoral-interior, Estado de São Paulo, Brasil). Os objetivos desse trabalho foram amostrar e caracterizar o componente arbóreo de florestas maduras da região metropolitana de São Paulo, SP, Brasil, verificar a existência de variações florísticas ao longo dos planaltos da região no sentido litoral-interior e quais fatores ambientais que poderiam influenciá-la. Além disso, são realizadas considerações sobre a classificação e conservação dessas florestas. Foram amostradas três florestas maduras da região metropolitana, situadas nos municípios de São Paulo (Marsilac), Cotia (Reserva Florestal do Morro Grande) e Itapevi. Em cada localidade foram instaladas duas parcelas de $20 \times 50 \mathrm{~m}$ com amostragem dos indivíduos com perímetro a $1,30 \mathrm{~m}$ de altura do solo $\mathrm{PAP} \geq 15 \mathrm{~cm}$. Posteriormente, foram realizadas análises de agrupamento (UPGMA) e ordenação (DCA) com dados de densidade das espécies. O levantamento resultou na amostragem de 943 indivíduos arbóreos pertencentes a 50 famílias, 109 gêneros e 184 espécies; índice de Shannon 4,62, equabilidade de Pielou 0,88, área basal de $46,1 \mathrm{~m}^{2} \mathrm{ha}^{-1} \mathrm{e}$ densidade de 1.572 ind ha ${ }^{-1}$. As análises de agrupamento e ordenação indicaram haver maior similaridade entre Marsilac e Morro Grande, com tendência à formação de um bloco florístico mais homogêneo, enquanto que Itapevi se isolou das demais. Essa variação foi atribuída à existência de um período seco mais acentuado no inverno na região de Itapevi, fator que possibilita a presença de algumas espécies comumente associadas a florestas estacionais semidecíduas. Ainda assim, foi verificado que as florestas da região metropolitana são compostas por uma flora predominantemente ombrófila, com maior ou menor presença de elementos de florestas estacionais semidecíduas, mistas ou frias/úmidas. A alta diversidade das florestas maduras, aliada à presença de uma grande quantidade de espécies raras e ameaçadas, além da escassez desses remanescentes, são razões para proteção e conservação imediata dessas florestas.

Palavras-chave: biodiversidade, clímax, conservação, fitogeografia, Mata Atlântica

1. Parte da Dissertação de Mestrado do primeiro Autor

2. Prefeitura Municipal de São Paulo, Herbário Municipal de São Paulo, Av. IV Centenário, 1268, Vila Lusitânia, 04030-000 São Paulo, SP, Brasil

3. Instituto de Botânica de São Paulo, Av. Miguel Stéfano, 3687, Água Funda, 04301-012 São Paulo, SP, Brasil

4. Autor para correspondência: ehpbarretto@bol.com.br 


\section{Introdução}

Grande parte da Mata Atlântica sofreu com intensas perturbações antrópicas, seja com a ocupação indígena ou europeia, esta última mais devastadora, de modo que grande parte das florestas atuais é secundária. Na região metropolitana de São Paulo (RMSP), esse também é o retrato existente dos ambientes naturais, de forma que remanescentes de florestas originais são muito raros (Catharino \& Aragaki 2008) e de características pouco conhecidas (Dislich et al. 2001).

Uma floresta tropical ou ombrófila densa pode ser considerada madura quando atinge níveis elevados de desenvolvimento, no qual pode ser caracterizado, de forma geral, como matas que apresentam alta biodiversidade, grandes árvores, abundância de epífitas, muitos estratos florestais e numerosas lianas lenhosas (Harlshorn 1980). Essas florestas, também chamadas de primitivas, originais, climácicas, primárias ou virgens, apresentam grandes diferenças estruturais e florísticas quando comparadas a florestas mais jovens, mesmo em locais próximos (Leitão-Filho 1982, Catharino 1989, Guapyassu 1994, Catharino et al. 2006, Rosário 2010). Por outro lado, quando uma floresta secundária atinge um alto nível de desenvolvimento, sua diferenciação de uma floresta primária não é uma tarefa simples. Mesmo Loefgren (1896) já dizia que é muito difícil, senão impossível, distinguir uma mata original (ou mata virgem) de um capoeirão, termo designado para florestas secundárias em estágio avançado de regeneração. Desse modo, capoeirões com alto grau de desenvolvimento também foram consideradas florestas maduras nesse trabalho.

Apesar da grande quantidade de trabalhos existentes sobre a flora da região metropolitana de São Paulo, poucos foram realizados em fragmentos de florestas maduras. Apenas alguns autores se propuseram a estudar essas florestas no Parque Estadual da Cantareira (Baitello et al. 1993, Arzolla 2002) e na Reserva Florestal do Morro Grande (Catharino et al. 2006, Rosário 2010). A falta de conhecimento sobre essas matas resulta em uma lacuna no conhecimento da composição florística e estrutural das florestas atlânticas regionais. Mesmo a Resolução CONAMA 01/94, que descreve os estágios sucessionais da Mata Atlântica do Estado de São Paulo, não caracteriza e tampouco define o que seriam florestas maduras do Estado. A raridade dessas matas, aliada à sua riqueza biológica e por representarem o que mais se aproximaria das florestas originais, as tornam de valor inestimável. Não é por acaso que tanto as florestas primitivas como aquelas em estágio avançado de regeneração da Mata Atlântica são proibidas de corte, salvo em casos de obras de utilidade pública (BRASIL 2006).

Os diversos autores que estudaram as florestas na região metropolitana chegaram a classificações fisionômicas e florísticas diversas, tornando-se um assunto recorrente nos trabalhos sobre a flora regional. Considerando os trabalhos mais recentes, grande parte dos autores classsificou as florestas locais como ombrófila densa (Veloso \& Góes-Filho 1982, Gomes 1992, Roizman 1993, Tomasulo 1995, IBGE 2004); enquanto alguns a consideraram como floresta estacional semidecidual (Rodrigues 1986, Morellato 1992, Gandolfi et al. 1995, Salis et al. 1995); e outros como uma flora de transição entre essas duas fitofisionomias (alguns autores também relatam a presença de elementos de cerrado e/ou florestas mistas), com maior ou menor predominância de alguma delas (Baitello et al. 1993, Aragaki \& Mantovani 1998, Garcia \& Pirani 2001, Catharino et al. 2006, Durigan et al. 2008). Estudando fragmentos florestais da região metropolitana no Planalto de Ibiúna, Durigan et al. (2008), relatou indícios de transição entre biomas, com a flora tendendo, ao sul dessa formação geológica, para floresta ombrófila densa e, ao norte, para floresta estacional semidecidual e cerrado.

Diante deste cenário, este trabalho teve como objetivos amostrar e caracterizar o componente arbóreo de florestas maduras da RMSP, verificar a existência de possíveis variações florísticas ao longo de um de um eixo de cerca de $50 \mathrm{~km}$ sobre os planaltos da RMSP no sentido litoral-interior e averiguar, caso haja alguma variação na flora, quais os fatores ambientais que estariam influenciando-a. Além disso, são realizadas considerações sobre a classificação das florestas da região metropolitana de São Paulo e sobre a importância da conservação das florestas maduras locais.

\section{Material e métodos}

Seleção e caracterização das áreas de estudo - Para localizar as florestas maduras da região metropolitana de São Paulo, foram pré-selecionados 50 fragmentos baseado em análise de fotografias aéreas, imagens de satélite e indicação de especialistas (figura 1). Posteriormente, cada fragmento foi visitado e avaliado conforme parâmetros consagrados na literatura para seleção de florestas maduras tropicais (Budowski 
1963, 1965, 1970, Guariguata \& Ostertag 2001), tais como: o porte (diâmetro e altura) e diversidade de espécies de árvores; abundância e diversidade de epífitas e lianas; riqueza do sub-bosque e histórico de pouca interferência antrópica nas áreas. A partir dessa avaliação, foram escolhidas três áreas de estudo (figura 1), localizadas no extremo sul do município de São Paulo, bairro de Marsilac (M), interior da Área de Proteção Ambiental Capivari-Monos; no oeste do município de Cotia, na Reserva Florestal do Morro Grande (Q); e em propriedades particulares situadas no oeste do município de Itapevi (I), SP.

As áreas selecionadas situam-se na região de ocorrência da floresta ombrófila densa montana do bioma Mata Atlântica (IBGE 2012) do Planalto Atlântico, embora em sub-compartimentos geológicos diferentes. Marsilac (M1: 323.840E e 7.352.799S; M2: 324.079E e 7.352.909S) localiza-se na borda sul das Morrarias de Embu do Planalto Paulistano, próximo à Serra do Mar, em altitudes de 750 m.s.m (M1) e 775 m.s.m (M2); Morro Grande (Q1: 295.710E e 7.371.318S; Q2: 296.429E e 7.371.542S) localiza-se no Planalto de Ibiúna (Q1: 975 m.s.m. e Q2: 950 m.s.m.); e Itapevi (I1: 293.176E e 7.391.820S; I2: 293.747E e 7.392.441S) situa-se na interface do Planalto de Ibiúna com a Serraria de São Roque (I1: 950 m.s.m. e I2: 975 m.s.m.). Todas as áreas selecionadas situam-se em terreno com inclinação inferior a $25 \%$.

Conforme a classificação climática de Setzer (1966) para o Estado de São Paulo (baseada em Koppen 1948), o clima predominante nas áreas de

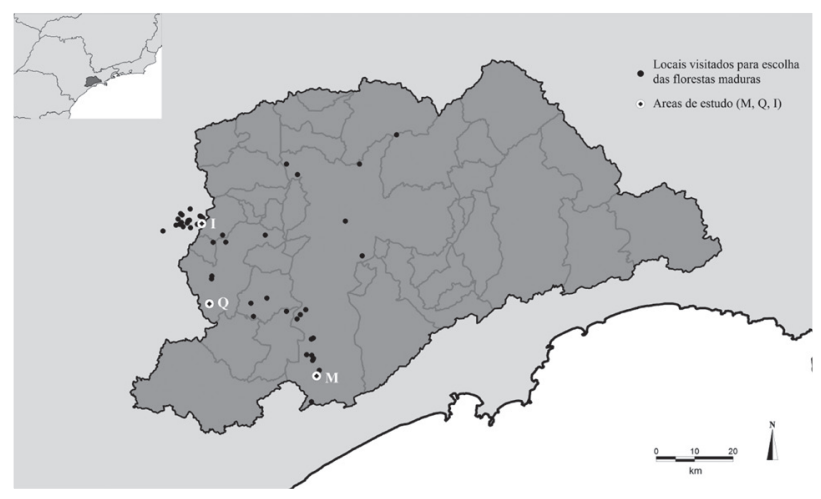

Figura 1. Localização das florestas avaliadas na região metropolitana de São Paulo, SP, Brasil e arredores para escolha das florestas atlânticas maduras, com indicação das áreas selecionadas. M: Marsilac, São Paulo; Q: Reserva Florestal do Morro Grande, Cotia; I: Itapevi.

Figure 1. Location of the investigated forests in the São Paulo metropolitan areas, São Paulo State, Brazil) and surrounding area for the mature Atlantic Forests choice, indicating the selected areas. M: Marsilac, São Paulo; Q: Morro Grande Forest Reserve, Cotia; I: Itapevi. estudo é do tipo temperado úmido $(\mathrm{Cfb})$. Para melhor caracterizar as condições climáticas das localidades escolhidas, foram obtidas no banco de dados climáticos da EMBRAPA (2003) as médias mensais (históricas) pluviométricas e de temperatura de estações meteorológicas existentes nas proximidades das áreas de estudo (figuras 2 e 3). Para Marsilac, foram utilizados dados de 1946 a 1970 da estação de Juquitiba (SP), distante $33 \mathrm{~km}$ das parcelas e localizada na mesma latitude e altitude $(291.283 \mathrm{E}$ e 7.351.101S; 750 m.s.m.). Para o Morro Grande, foram utilizados os dados de 1953 a 1970 da estação de Itapecerica da Serra (SP), situada a 20 km de distância, em latitude semelhante e altitude $100 \mathrm{~m}$ menor (316.225E e 7.368.814S; 850 m.s.m). Para Itapevi foram utilizados dados de 1941 a 1970 da estação de Cotia (SP), distante $11 \mathrm{~km}$ das parcelas e também com altitude $100 \mathrm{~m}$ menor (304.638E e 7.387.550S; 880 m.s.m.). Tanto para Itapevi quanto para o Morro Grande, foi feita uma correção de $0,5^{\circ} \mathrm{C}$ nas médias de temperatura das estações correspondentes, conforme Vasconcellos \& Tarifa (1982). Para cada localidade também foram obtidos gráficos de balanço hídrico (figura 4), baseado em Thornthwaite \& Mather (1955), também obtidos no banco de dados climáticos da EMBRAPA citado. Cabe ressaltar que esses gráficos foram obtidos diretamente no site da EMBRAPA, de modo que não foi possível realizar a correção de $0,5^{\circ} \mathrm{C}$.

Em relação ao histórico das áreas, o proprietário de uma das áreas de estudo de Itapevi (I1) afirma que a floresta já existia na década de 1940 e nunca foi cortada desde a aquisição da propriedade. No entanto, relata um grande incêndio na região, no início da década de 1960, comprometendo parte da vegetação que existia em sua propriedade. Ainda hoje é possível observar sinais de fogo em algumas árvores de grande porte. Apesar disso, a mata permaneceu com trechos preservados, mantendo parte da estrutura primitiva da floresta. Da mesma forma, a região da área de estudo I 2 também é um remanescente antigo, com árvores frondosas ocupando o dossel, como jetiquibás (Cariniania spp.) e guatambus (Aspidosperma spp.), embora apresente mais indícios de perturbação, principalmente no sub-bosque, evidenciada pela maior presença de espécies pioneiras e secundárias iniciais.

$\mathrm{Na}$ Reserva Florestal do Morro Grande, Catharino (2006) relatou que algumas áreas foram completamente devastadas para o cultivo, outras foram abandonadas após intensa perturbação e algumas manchas de floresta, como a área de estudo 
Q1, seriam remanescentes primitivos relativamente pouco perturbados. A área de estudo Q2 situa-se em um trecho que se assemelha à fisionomia de um capoeirão com alto grau de desenvolvimento. Ambas as áreas situam-se sobre quadrantes instalados por Catharino (2006) em trechos "espantosamente exuberantes", classificados pelo autor como florestas maduras. Apesar disso, são remanescentes onde já houve, possivelmente, o corte seletivo de madeiras mais nobres e de palmito-juçara (Euterpe edulis).

Marsilac (M1 e M2) situa-se em área particular de um proprietário que adquiriu as terras há 15 anos. Anteriormente, a área fazia parte de uma fazenda que preservou algumas áreas de mata. $\mathrm{O}$ antigo proprietário não foi localizado e as informações sobre as atividades pretéritas são escassas. Em conversas com alguns moradores vizinhos à área, foi relatado que parte dessas florestas nunca foi submetida ao corte raso, provável condição de $\mathrm{M} 2$, um remanescente primitivo pouco alterado. No entanto, da mesma forma que as outras áreas, já houve, provavelmente, o corte seletivo de madeiras nobres, extração de palmito e de folhas de guaricanga (Geonoma spp.). Já a área de estudo M1 situa-se em um mosaico de florestas primitivas pouco alteradas e capoeirões com alto grau de desenvolvimento.

Amostragem - Em cada uma das três áreas selecionadas foram instaladas duas parcelas de $20 \times 50 \mathrm{~m}$, subdivididas em parcelas de $10 \times 10 \mathrm{~m}$, totalizando $6.000 \mathrm{~m}^{2}$ de área total de amostragem. As parcelas

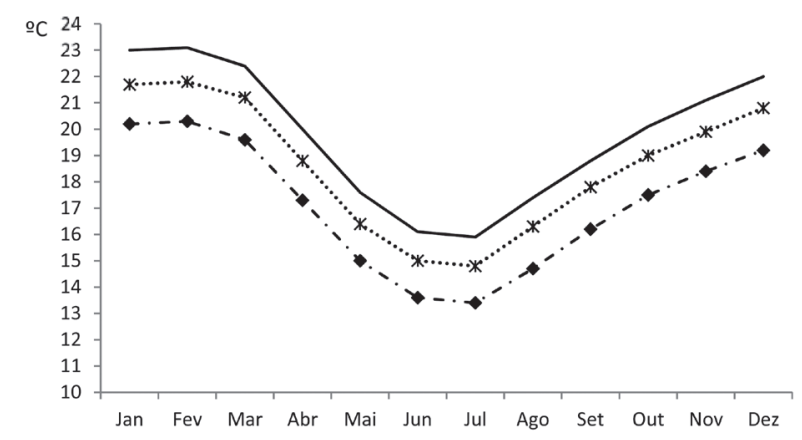

Figura 2. Médias mensais históricas de temperatura referente às três florestas estudadas na região metropolitana de São Paulo, SP, Brasil. ...*... Itapevi; - - -.. Reserva Florestal do Morro Grande, Cotia; —— Marsilac, São Paulo. Fonte: adaptado de EMBRAPA (2003).

Figure 2. Historical monthly means for temperature of three forests from São Paulo metropolitan area, São Paulo State, Brazil. $\cdots *$ Itapevi; $\cdots \cdots$ Morro Grande Forest Reserve, Cotia; — Marsilac, São Paulo. Source: adapted from EMBRAPA (2003). foram montadas utilizando canos PVC, fixados a cada dez metros, possibilitando reamostragem futura. Foram mensurados todos os indivíduos arbóreos (incluindo fetos arborescentes, palmeiras e indivíduos mortos) com perímetro a $1,30 \mathrm{~m}$ de altura do solo $(\mathrm{PAP}) \geq 15 \mathrm{~cm}$. Foram coletadas amostras de todos os indivíduos arbóreos presentes nas parcelas, sempre que possível de material fértil, com utilização de tesoura de poda alta e de escaladores para coleta das árvores mais altas, sendo uma das etapas mais demoradas do estudo. As coletas foram realizadas durante um período de dois anos e meio, de $01 / 2012$ a 06/2014. As alturas foram estimadas com auxílio da própria tesoura de poda alta $(10,5 \mathrm{~m})$ e de um telêmetro. O material botânico coletado foi herborizado conforme Fidalgo \& Bononi (1984) e os "voucher" foram depositados no herbário PMSP.

Análise dos dados - A identificação das espécies foi feita com base em literatura especializada, em comparações com exsicatas no Herbário Municipal de São Paulo (PMSP), Herbário Maria Eneyda P.K. Fidalgo (SP) e Herbário Dom Bento Pickel (SPSF), além de consulta a especialistas. A classificação das famílias foi baseada no sistema taxonômico APG III (2009) e a nomenclatura das espécies seguiu aquela adotada pela Flora do Brasil (Forzza et al. 2013).

Foram calculados, pelo software Fitopac 2.1 (Shepherd 2010), os descritores quantitativos usuais para a comunidade (Mueller-Dombois \& Ellenberg 1974), o índice de diversidade de Shannon em base neperiana e a

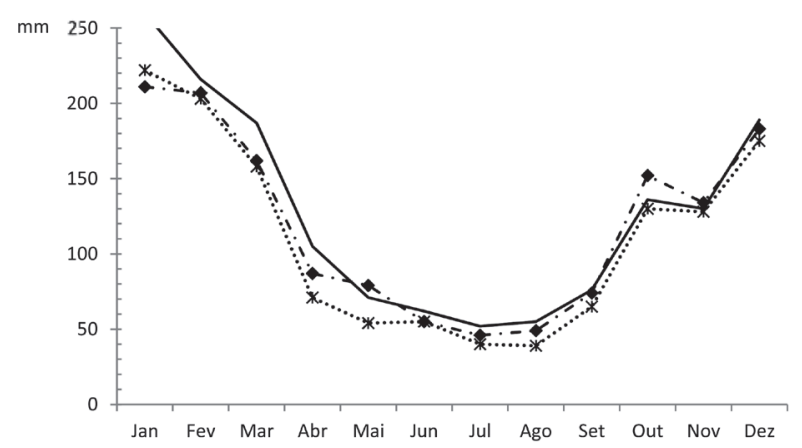

Figura 3. Médias mensais históricas de pluviosidade referente às três florestas estudadas na região metropolitana de São Paulo, SP, Brasil. ...*... Itapevi; - $\rightarrow$ Reserva Florestal do Morro Grande, Cotia; - Marsilac, São Paulo Fonte: EMBRAPA (2003).

Figure 3. Historical monthly means for rainfall of three forests from São Paulo metropolitan area, São Paulo State, Brazil. ...*... Itapevi; -. $\gg$ Morro Grande Forest Reserve, Cotia; — Marsilac, São Paulo. Source: EMBRAPA (2003). 
equabilidade (Pielou 1975). Os cálculos foram realizados considerando a amostragem total e as localidades isoladamente (Marsilac, Morro Grande e Itapevi). Cabe ressaltar que os indivíduos mortos também foram registrados na amostragem, mas não foram considerados nas análises estruturais. $\mathrm{O}$ esforço amostral foi verificado com a curva de rarefação para a amostragem total e para cada localidade a partir de 100 aleatorizações, com auxílio do software Past 2.17c (Hammer et al. 2001). Para estimar a riqueza foram usados os estimadores ACE, Chao-1, Jackknife-1 e Jackknife-2, com a utilização do software EstimateS (Colwell 2013).

Foi efetuada uma classificação sucessional das espécies baseada em Gandolfi (1991, 2000), adotando-se as categorias pioneira, secundária inicial e secundária tardia. Foram consideradas pioneiras as espécies de ciclo de vida curto, com crescimento rápido, madeira de baixa densidade $\mathrm{e}$ amplamente dependentes de alta luminosidade para estabelecimento e reprodução. Secundárias iniciais também foram consideradas espécies com crescimento
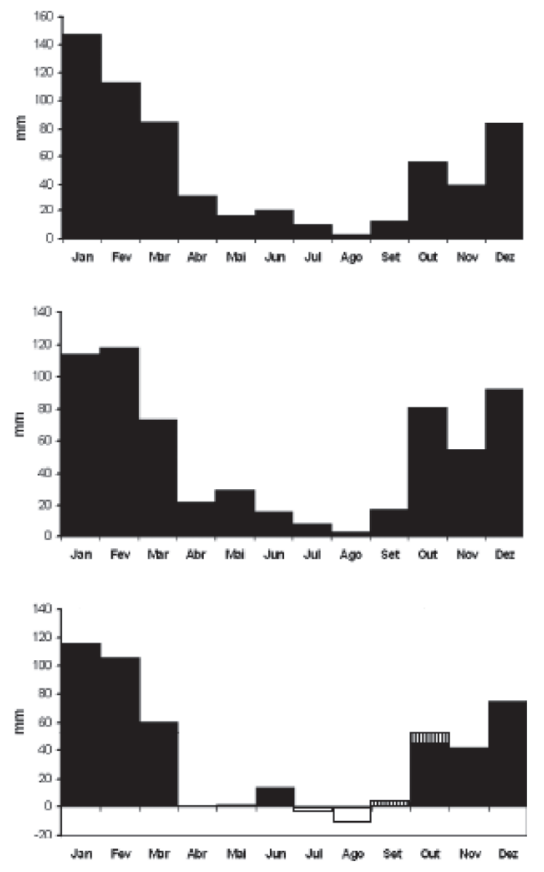

Figura 4. Balanço hídrico mensal referente às três florestas estudadas da região metropolitana de São Paulo, SP, Brasil. a. Marsilac, São Paulo; b. Reserva Florestal do Morro Grande, Cotia; c. Itapevi. $\equiv$ Deficiência, $\square$ Excedente, $\square$ Retirada, 盂Reposição. Fonte: adaptado de EMBRAPA (2003).

Figure 4. Monthly water balance of three forests from São Paulo metropolitan area, São Paulo State, Brazil. a. Marsilac, São Paulo; b. Morro Grande Forest Reserve, Cotia; c. Itapevi. 三Deficit, Surplus, $\square$ Withdrawal, III Restore. Source: adapted from EMBRAPA (2003). rápido, madeira de baixa densidade, ciclo de vida mais longo que as pioneiras e dependentes de luminosidade para o desenvolvimento, embora possam ocorrer em condições de meia sombra. Foram consideradas secundárias tardias tanto as espécies que completam todo o seu ciclo de vida à sombra de outras árvores (espécies típicas de sub-bosque) quanto espécies longevas, tolerantes à sombra na fase juvenil, com crescimento lento, madeira de alta densidade e típicas do dossel de florestas maduras. O enquadramento das espécies nas categorias foi realizado a partir da pesquisa de dados em literatura (Gandolfi 1991, Leitão-Filho 1993, Gandolfi et al. 1995, Bernacci et al. 2006, Catharino et al. 2006) e de observações pessoais.

Foi realizada uma classificação das espécies quanto às síndromes de dispersão (zoocóricas, autocóricas e anemocóricas), baseada nos conceitos de Pijl (1982) e em literatura (Bernacci et al. 2006, Catharino et al. 2006). Além disso, foram classificadas quanto ao status de conservação, segundo as listas oficiais de espécies ameaçadas de extinção (SMA 2004, MMA 2008, IUCN 2013, Martinelli \& Moraes 2013).

Para verificar a similaridade florística entre as parcelas amostradas, foram usados o índice de Jaccard e análises de agrupamento Unweighted Pair Group Method with Arithmetic Mean - UPGMA (Valentim 2000) entre as parcelas de $20 \times 50 \mathrm{~m}$ e entre as subparcelas de $10 \times 10 \mathrm{~m}$, com a utilização do coeficiente de Bray Curtis (dados de densidade das espécies).

Para averiguar a existência de gradientes florísticos, foram utilizadas técnicas de ordenação, a partir do método Detrended Correspondence Analysis - DCA (Hill \& Gauch 1980), entre as parcelas de $20 \times 50 \mathrm{~m}$ e entre as sub-parcelas de $10 \times 10 \mathrm{~m}$ (com dados de densidade das espécies). Os cálculos de similaridade, agrupamento e ordenação foram realizados com auxílio dos softwares Past 2.17c (Hammer et al. 2001), Fitopac 2.1 (Shepherd 2010) e PC-ORD (McCune \& Mefford 2011). Os resultados obtidos foram comparados com dados de altitude, distância entre as localidades, tipo de solo predominante (segundo Oliveira et al. 2009 e observações em campo), médias mensais de temperatura, pluviometria e balanço hídrico. Os dados climáticos foram obtidos de EMBRAPA (2003), conforme citado anteriormente.

\section{Resultados}

Composição florística e estrutural - Foram amostrados 943 indivíduos arbóreos, distribuídos em 184 
espécies, 50 famílias e 109 gêneros (tabela 1), sendo uma espécie exótica (Citrus sp.). Os parâmetros estruturais e de diversidade são apresentados na tabela 2. Se considerássemos todas as parcelas juntas, o índice de Shannon da comunidade seria de 4,62 e a área basal média de $46,1 \mathrm{~m}^{2} \mathrm{ha}^{-1}(44,4$ a $49,3 \mathrm{~m}^{2} \mathrm{ha}^{-1}$ ). Em relação à densidade, os valores médios obtidos foram de 1.572 ind $^{-1} \mathrm{~h}^{-1}$, variando de 1.380 a 1.910 ind ha $^{-1}$ e equabilidade média de 0,88 , variando de 0,89 a 0,93 . Marsilac foi a localidade que apresentou maior quantidade de espécies (103), maior índice de Shannon $(4,29)$, equabilidade $(0,92)$ e maior área basal média $\left(49,3 \mathrm{~m}^{2}\right)$. Morro Grande e Itapevi apresentaram valores próximos de Shannon (4,02 e 3,99, respectivamente), embora o primeiro tenha registrado maior número de espécies (97) que o segundo (91).

As famílias Myrtaceae e Lauraceae foram as mais ricas em espécies em todas as localidades e na amostragem total. Das 50 famílias registradas, 22 delas ocorreram em todas as localidades. Itapevi apresentou maior número de famílias exclusivas (Cardiopteridaceae, Caricaceae, Lecythidaceae, Moraceae, Myristicaceae, Phyllanthaceae e Vochysiaceae), enquanto que Morro Grande e Marsilac compartilharam maior número entre si (29, sendo sete exclusivas das duas: Asteraceae, Cyatheaceae, Polygonaceae, Primulaceae, Proteaceae, Symplocaceae e Winteraceae). As figuras 5 e 6 apresentam os dados de riqueza e densidade das famílias amostradas.

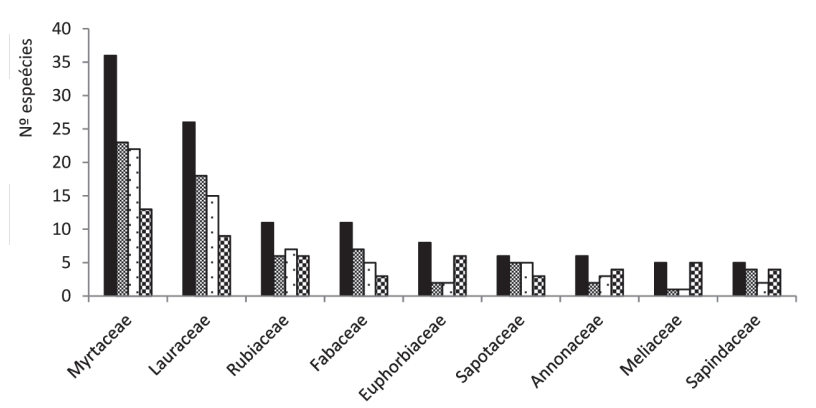

Figura 5. Riqueza das famílias das árvores que ocorreram com cinco ou mais espécies em três florestas atlânticas maduras amostradas da região metropolitana de São Paulo, SP, Brasil. Marsilac, São Paulo; $\square$ Reserva Florestal do Morro Grande, Cotia; $⿴ 囗 十$ Itapevi, $\square$ Total.

Figure 5. Richness of families of trees that had at least five species sampled on three mature Atlantic Forests from São Paulo metropolitan area, São Paulo State, Brazil. Marsilac, São Paulo; -1 Morro Grande Forest Reserve, Cotia; 1 Itapevi, Total.
Os gêneros mais ricos na amostragem total (figura 7) foram Ocotea (16) e Eugenia (14), que somados representaram $27,5 \%$ de todas as espécies amostradas. Considerando as localidades isoladamente, Eugenia e Ocotea foram responsáveis por cerca de $20 \%$ das espécies amostradas tanto no Morro Grande quanto em Marsilac, e 11\% em Itapevi.

As espécies que apresentaram maiores valores de densidade na amostragem total foram Rudgea jasminoides, Guapira opposita, Ocotea catharinensis e Calyptranthes lucida. Apenas Guapira opposita esteve entre as dez mais abundantes em todas as localidades. Euterpe edulis, Ocotea catharinensis e Calyptranthes lucida estiveram entre as mais abundantes no Morro Grande e em Marsilac, enquanto Rudgea jasminoides e Myrcia tijucensis apresentaram valores altos de densidade no Morro Grande e em Itapevi. As figuras 8 e 9 apresentam as dez espécies com maiores valores de densidade na amostragem total e por localidade.

Distribuição diamétrica e estratificação florestal Em relação distribuição diamétrica, observa-se uma grande quantidade de indivíduos com diâmetros pequenos, principalmente entre $5-10 \mathrm{~cm}$, e progressiva diminuição da quantidade de árvores em direção aos diâmetros maiores (figura 10). Os maiores diâmetros obtidos foram de Sloanea lasiocoma $(107 \mathrm{~cm})$ e Aspidosperma olivaceum (95 cm), em Itapevi e Micropholis crassipedicellata, tanto no Morro Grande quanto em Marsilac (88 e $92 \mathrm{~cm}$, respectivamente).

Em relação à estratificação vertical, observa-se uma concentração maior de indivíduos na faixa

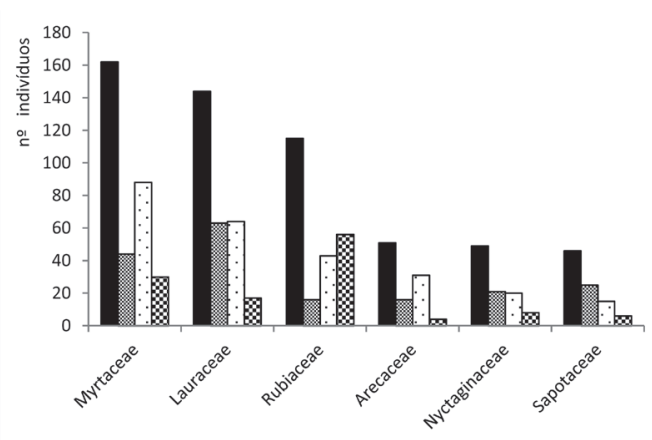

Figura 6. Famílias com maior número de indivíduos arbóreos em três florestas atlânticas maduras da região metropolitana de São Paulo, SP, Brasil. Marsilac, São Paulo; $\square$ Reserva Florestal do Morro Grande, Cotia; $\$$ Itapevi, $\square$ Total.

Figure 6. Most representative families (number of individuals) of three mature Atlantic Forests from São Paulo metropolitan area, São Paulo State, Brazil. Marsilac, São Paulo; :- Morro Grande Forest Reserve, Cotia; $\mathbb{B}$ Itapevi, Total. 
Tabela 1. Lista de árvores amostradas em três florestas maduras de Mata Atlântica da região metropolitana de São Paulo, SP, Brasil. CS: classificação sucessional; SD: síndrome de dispersão; Ni: número de indivíduos; M: Marsilac, São Paulo; Q: Reserva Florestal do Morro Grande, Cotia; I: Itapevi; $\mathrm{N}^{\circ} \mathrm{Col}$ : número de coletor; PI: espécie pioneira; SI: secundária inicial; ST: secundária tardia; ZOO: zoocórica; ANE: anemocórica; AUT: autocórica; * espécies ameaçadas de extinção, segundo SMA (2004), MMA (2008), Martinelli \& Moraes (2013) e IUCN (2013).

Table 1. List of tree sampled in three mature Atlantic Forests from São Paulo metropolitan area, SP, Brazil. CS: successional group; SD: dispersion syndrome; Ni: number of individuals; M: Marsilac, São Paulo; Q: Morro Grande Forest Reserve, Cotia; I: Itapevi; $\mathrm{N}^{\circ} \mathrm{Col}$ : specimen collector name and number; PI: pioneer species; SI: early secondary; ST: late secondary; ZOO: zoochorous; ANE: anemochorous; AUT: autochorous; * Threatened species, according SMA (2004), MMA (2008), Martinelli \& Moraes (2013) and IUCN (2013).

\begin{tabular}{|c|c|c|c|c|c|c|}
\hline \multirow{2}{*}{ Família/espécie } & \multirow{2}{*}{$\mathrm{CS}$} & \multirow{2}{*}{ SD } & \multicolumn{3}{|c|}{$\mathrm{Ni}$} & \multirow{2}{*}{$\mathrm{N}^{\circ} \mathrm{Col}$} \\
\hline & & & $\mathrm{M}$ & Q & I & \\
\hline \multicolumn{7}{|l|}{ Anacardiaceae } \\
\hline Tapirira guianensis Aubl. & ST & $\mathrm{ZOO}$ & & 4 & 3 & ЕНРB01 \\
\hline \multicolumn{7}{|l|}{ Annonaceae } \\
\hline Annona cacans Warm. & SI & $\mathrm{ZOO}$ & & & 1 & ЕНРВ03 \\
\hline Annona neosericea H.Rainer & SI & $\mathrm{ZOO}$ & & 1 & 2 & ЕНРВ05 \\
\hline Annona sylvatica A.St.-Hil. & SI & $\mathrm{ZOO}$ & & & 2 & ЕНРB04 \\
\hline Duguetia salicifolia R.E.Fr.* & ST & $\mathrm{ZOO}$ & & 1 & & ЕНРB07 \\
\hline Guatteria australis A.St.-Hil. & ST & $\mathrm{ZOO}$ & 1 & 3 & 4 & ЕНРB08 \\
\hline Xylopia langsdorfiana A.St.-Hil. \& Tul. & ST & $\mathrm{ZOO}$ & 1 & & & ЕНPB437 \\
\hline \multicolumn{7}{|l|}{ Apocynaceae } \\
\hline Aspidosperma olivaceum Mull.Arg. & ST & ANE & 1 & 3 & 4 & EHPB11 \\
\hline Aspidosperma polyneuron Mull.Arg.* & ST & ANE & & & 1 & EHPB12 \\
\hline \multicolumn{7}{|l|}{ Aquifoliaceae } \\
\hline Ilex dumosa Reissek & ST & $\mathrm{ZOO}$ & 1 & & & EHPB13 \\
\hline Ilex microdonta Reissek & ST & $\mathrm{ZOO}$ & 1 & & & EHPB153 \\
\hline Ilex theezans Mart. ex Reissek & SI & $\mathrm{ZOO}$ & 1 & & & EHPB154 \\
\hline \multicolumn{7}{|l|}{ Araliaceae } \\
\hline Schefflera angustissima (Marchal) Frodin & SI & $\mathrm{ZOO}$ & 1 & 1 & 1 & EHPB14 \\
\hline \multicolumn{7}{|l|}{ Arecaceae } \\
\hline Euterpe edulis Mart.* & ST & $\mathrm{ZOO}$ & 10 & 14 & & \\
\hline Geonoma schottiana Mart. & $\mathrm{ST}$ & $\mathrm{ZOO}$ & & & 4 & EHPB16 \\
\hline Lytocaryum hoehnei (Burret) Toledo & ST & $\mathrm{ZOO}$ & 6 & 17 & & EHPB17 \\
\hline \multicolumn{7}{|l|}{ Asteraceae } \\
\hline Piptocarpha macropoda (DC.) Baker & PI & ANE & & 1 & & EHPB18 \\
\hline Vernonanthura divaricata (Spreng) H.Rob. & PI & ANE & 2 & & & EHPB19 \\
\hline \multicolumn{7}{|l|}{ Bignoniaceae } \\
\hline Cybistax antisyphilitica (Mart.) Mart. & $\mathrm{ST}$ & ANE & & & 1 & EHPB54 \\
\hline Handroanthus impetiginosus Mattos & ST & ANE & & 1 & & EHPB55 \\
\hline Jacaranda puberula Cham. & SI & ANE & & & 1 & EHPB155 \\
\hline \multicolumn{7}{|l|}{ Boraginaceae } \\
\hline Cordia sellowiana Cham. & SI & $\mathrm{ZOO}$ & 1 & 2 & 2 & ЕНРB20 \\
\hline
\end{tabular}


Tabela 1 (continuação

Família/espécie

\begin{tabular}{ccccc}
\multirow{C}{*}{$\mathrm{CS}$} & $\mathrm{SD}$ & \multicolumn{2}{c}{$\mathrm{Ni}$} & \\
& $\mathrm{M} \quad \mathrm{Q}$ & $\mathrm{I}$ & \\
& &
\end{tabular}

Burseraceae

Protium kleinii Cuatrec.*

ST ZOO 2

EHPB21

Cardiopteridaceae

Citronella paniculata (Mart.) R.A.Howard

SI ZOO

5

EHPB22

Caricaceae

Jacaratia heptaphylla (Vell.) A.DC

SI ZOO

4

EHPB31

Celastraceae

Maytenus cestrifolia Reissek

$\begin{array}{llll}\text { ST } & \text { ZOO } & 1 & 1\end{array}$

EHPB27

Maytenus gonoclada Mart.

$\begin{array}{llll}\text { ST } & \mathrm{ZOO} & 1 & 1\end{array}$

EHPB28

Tontelea leptophylla A.C.Sm.*

EHPB29

Chrysobalanaceae

Hirtella hebeclada Moric. ex DC.

ST $\quad$ ZOO 14

EHPB23

Clusiaceae

Garcinia gardneriana (Planch. \& Triana) Zappi

$\begin{array}{lllll}\text { ST } & \text { ZOO } & 1 & 3 & 1\end{array}$

EHPB52

Combretaceae

Buchenavia kleinii Exell

ST ZOO 2

EHPB156

Cunoniaceae

Lamanonia ternata Vell.

$\begin{array}{lll}\text { ST } & \text { ZOO } & 1\end{array}$

EHPB53

Weinmannia paulliniifolia Pohl ex Ser.

SI ANE 3

EHPB157

Cyatheaceae

Cyathea delgadii Sternb.

Cyathea dichromatolepis (Fée) Domin

Cyathea phalerata Mart.

SI ANE 1

EHPB24

ST ANE 3

EHPB25

ST ANE 14

EHPB26

Elaeocarpaceae

Sloanea hirsuta (Schott) Planch. ex Benth.

Sloanea lasiocoma K.Schum.

ST $\begin{array}{llll}\mathrm{ZOO} & 2 & 4\end{array}$

EHPB32

ST ZOO

EHPB33

Euphorbiaceae

Actinostemon concolor (Spreng.) Mull.Arg.

SI AUT

EHPB37

Alchornea glandulosa Poepp. \& Endl.

SI ZOO

EHPB34

Alchornea sidifolia Mull.Arg.

SI ZOO

EHPB36

Alchornea triplinervia (Spreng.) Mull.Arg.

SI ZOO

4

EHPB35

Croton floribundus Spreng.

PI AUT

EHPB39

Croton macrobothrys Baill.

PI AUT

EHPB40

Pera glabrata (Schott) Poepp. ex Baill.

SI ZOO 1

EHPB158

Pera heteranthera (Schrank) I.M.Johnst.

SI $\quad \mathrm{ZOO} \quad 6$

EHPB159

Fabaceae

Cassia ferruginea (Schrad.) Schrad. ex DC.

ST AUT

1

EHPB42 
Tabela 1 (continuação

\begin{tabular}{|c|c|c|c|c|c|c|}
\hline \multirow{2}{*}{ Família/espécie } & \multirow{2}{*}{$\mathrm{CS}$} & \multirow{2}{*}{ SD } & \multicolumn{3}{|c|}{$\mathrm{Ni}$} & \multirow{2}{*}{$\mathrm{N}^{\circ} \mathrm{Col}$} \\
\hline & & & M & Q & I & \\
\hline Copaifera lucens Dwyer & ST & $\mathrm{ZOO}$ & 1 & & & EHPB161 \\
\hline Copaifera trapezifolia Hayne & ST & $\mathrm{ZOO}$ & 1 & 1 & & EHPB310 \\
\hline Hymenaea courbaril L. & ST & $\mathrm{ZOO}$ & & 2 & & EHPB44 \\
\hline Inga lenticellata Benth.* & ST & $\mathrm{ZOO}$ & & 1 & & EHPB45 \\
\hline Inga sellowiana Benth.* & SI & $\mathrm{ZOO}$ & 4 & 1 & 2 & EHPB46 \\
\hline Platymiscium floribundum Vogel & ST & ANE & & & 2 & EHPB48 \\
\hline Pterocarpus rohrii Vahl. & ST & ANE & 1 & & & EHPB49 \\
\hline Tachigali denudata (Vogel) Oliveira-Filho & ST & ANE & 3 & & & EHPB312 \\
\hline Tachigali sp. & & ANE & 2 & 1 & & EHPB162 \\
\hline Fabaceae 1 & & & 1 & & & EHPB160 \\
\hline \multicolumn{7}{|l|}{ Lauraceae } \\
\hline Aniba firmula (Nees \& Mart.) Mez & ST & $\mathrm{ZOO}$ & & & 1 & EHPB118 \\
\hline Aniba viridis $\mathrm{Mez}$ & ST & $\mathrm{ZOO}$ & 1 & & & EHPB121 \\
\hline Beilschmiedia emarginata (Meisn.) Kosterm. & ST & $\mathrm{ZOO}$ & 4 & 2 & & EHPB 130 \\
\hline Cinnamomum hirsutum Lorea - Hern ${ }^{1}$ & ST & $\mathrm{ZOO}$ & & 1 & & EHPB132 \\
\hline Cryptocarya aschersoniana $\mathrm{Mez}$ & ST & $\mathrm{ZOO}$ & & & 2 & EHPB128 \\
\hline Cryptocarya mandioccana Meisn. & ST & $\mathrm{ZOO}$ & & 1 & 2 & EHPB127 \\
\hline Cryptocarya micrantha Meisn. & ST & $\mathrm{ZOO}$ & 2 & & & EHPB272 \\
\hline Cryptocarya saligna Mez. & ST & $\mathrm{ZOO}$ & 8 & 6 & & EHPB139 \\
\hline Endlicheria paniculata (Spreng.) J.F.Macbr. & ST & $\mathrm{ZOO}$ & & & 1 & EHPB163 \\
\hline Nectandra oppositifolia Nees & SI & $\mathrm{ZOO}$ & & 1 & & EHPB126 \\
\hline Ocotea aciphylla (Nees \& Mart.) Mez & ST & $\mathrm{ZOO}$ & 1 & 1 & & EHPB125 \\
\hline Ocotea catharinensis Mez.* & ST & $\mathrm{ZOO}$ & 12 & 25 & 2 & EHPB131 \\
\hline Ocotea corymbosa (Meisn.) Mez & ST & $\mathrm{ZOO}$ & & & 3 & EHPB133 \\
\hline Ocotea daphnifolia (Meisn.) Mezv * & ST & $\mathrm{ZOO}$ & 3 & 6 & & EHPB134 \\
\hline Ocotea dispersa (Nees \& Mart.) Mez & ST & $\mathrm{ZOO}$ & 5 & 6 & & EHPB135 \\
\hline Ocotea elegans $\mathrm{Mez}$ & ST & $\mathrm{ZOO}$ & 5 & 7 & 1 & EHPB136 \\
\hline Ocotea glaziovii Mez & ST & $\mathrm{ZOO}$ & 3 & & & EHPB122 \\
\hline Ocotea leucoxylon (Sw.) Laness. & ST & $\mathrm{ZOO}$ & 1 & & & EHPB273 \\
\hline Ocotea nectandrifolia $\mathrm{Mez} *$ & ST & $\mathrm{ZOO}$ & 2 & 1 & & EHPB143 \\
\hline Ocotea odorifera (Vell.) Rohwer * & ST & $\mathrm{ZOO}$ & 4 & 1 & & EHPB129 \\
\hline Ocotea pulchella (Nees \& Mart.) Mez & SI & $\mathrm{ZOO}$ & 1 & & & EHPB138 \\
\hline Ocotea pulchra Vattimo-Gil & ST & $\mathrm{ZOO}$ & 1 & & & EHPB120 \\
\hline Ocotea silvestris Vattimo-Gil & ST & $\mathrm{ZOO}$ & 3 & 1 & 2 & EHPB123 \\
\hline Ocotea teleiandra (Meisn.) Mez & ST & $\mathrm{ZOO}$ & 2 & & & EHPB119 \\
\hline Ocotea venulosa (Nees) Baitello & ST & $\mathrm{ZOO}$ & 5 & 4 & 3 & EHPB137 \\
\hline Ocotea sp. $1^{2}$ & & $\mathrm{ZOO}$ & & 1 & & EHPB142 \\
\hline
\end{tabular}


Tabela 1 (continuação

Família/espécie

\begin{tabular}{ccccc}
\multirow{C}{*}{$\mathrm{CS}$} & $\mathrm{SD}$ & \multicolumn{2}{c}{$\mathrm{Ni}$} & $\mathrm{N}^{\circ} \mathrm{Col}$
\end{tabular}

Lecythidaceae

Cariniana estrellensis (Raddi) Kuntze

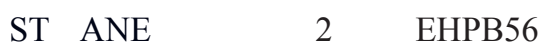

Malpighiaceae

Byrsonima ligustrifolia A.Juss.

$\begin{array}{llllll}\mathrm{ST} & \mathrm{ZOO} & 4 & 3 & 1 & \text { EHPB61 }\end{array}$

Melastomataceae

Miconia budlejoides Triana

$\begin{array}{lllll}\text { PI } & Z O O & 1 & 2 & \text { EHPB62 }\end{array}$

Miconia cabucu Hoehne

$\begin{array}{llll}\text { SI } & \text { ZOO } & 2 & \text { EHPB114 }\end{array}$

Mouriri chamissoana Cogn.

$\begin{array}{llll}\text { ST } & \text { ZOO } & 1 & \text { EHPB64 }\end{array}$

Meliaceae

Cabralea canjerana (Vell.) Mart.

Cedrela fissilis Vell.*

$\begin{array}{llllll}\text { ST } & \text { ZOO } & 4 & 5 & 1 & \text { EHPB67 }\end{array}$

Guarea macrophylla Vahl

$\begin{array}{llll}\text { ST } & \text { ANE } & 1 & \text { EHPB69 }\end{array}$

Trichilia lepidota Mart.

$\begin{array}{llll}\text { SI ZOO } & 6 & \text { EHPB70 }\end{array}$

Trichilia silvatica C.DC.*

$\begin{array}{llll}\text { ST } & \text { ZOO } & 1 & \text { EHPB164 }\end{array}$

$\begin{array}{llll}\text { ST } & \text { ZOO } & 1 & \text { EHPB71 }\end{array}$

Monimiaceae

Mollinedia boracensis Peixoto *

Mollinedia triflora (Spreng.) Tul.

$\begin{array}{llllll}\text { ST } & \text { ZOO } & 7 & 1 & \text { EHPB165 }\end{array}$

Mollinedia uleana Perkins

$\begin{array}{llllll}\text { ST } & Z O O & 8 & 3 & 1 & \text { EHPB166 }\end{array}$

Moraceae

Brosimum glaziovii Taub.*

Sorocea bonplandii (Baill.) W.C.Burger et al.

$\begin{array}{llllll}\text { ST } & \text { ZOO } & 3 & 3 & 8 & \text { EHPB167 }\end{array}$

Myristicaceae

Virola bicuhyba (Schott ex Spreng.) Warb.*

Myrtaceae

Calyptranthes grandifolia O.Berg

Calyptranthes lucida Mart. ex DC.

Calyptranthes dryadica M.L.Kawas.*

Campomanesia guaviroba (DC.) Kiaersk.

Eugenia beaurepairiana (Kiaersk.) D.Legrand

Eugenia capitulifera O.Berg

Eugenia cerasiflora Miq.

Eugenia copacabanensis Kiaersk.*

Eugenia dodonaeifolia Cambess.

Eugenia excelsa O.Berg

Eugenia ligustrina (Sw.) Willd.

$\begin{array}{llll}\text { ST } & \text { ZOO } & 1 & \text { EHPB168 }\end{array}$

$\begin{array}{llll}\text { ST } & \text { ZOO } & 1 & \text { EHPB169 }\end{array}$

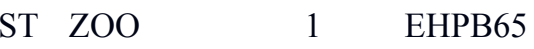

Eugenia neoverrucosa Sobral

Eugenia prasina O.Berg *

$\begin{array}{lccccc}\text { ST } & \text { ZOO } & 4 & 3 & 1 & \text { EHPB170 } \\ \text { ST } & \text { ZOO } & 7 & 30 & 1 & \text { EHPB171 } \\ \text { ST } & \text { ZOO } & 1 & & & \text { EHPB204 } \\ \text { ST } & \text { ZOO } & 1 & & & \text { EHPB172 } \\ \text { ST } & \text { ZOO } & 1 & 1 & & \text { EHPB173 } \\ \text { ST } & \text { ZOO } & & 4 & & \text { EHPB175 } \\ \text { ST } & \text { ZOO } & & 1 & & \text { EHPB176 } \\ \text { ST } & \text { ZOO } & & 1 & & \text { EHPB177 } \\ \text { SI } & \text { ZOO } & 1 & 3 & 2 & \text { EHPB178 } \\ \text { ST } & \text { ZOO } & 2 & 4 & 2 & \text { EHPB179 } \\ \text { ST } & \text { ZOO } & & & 1 & \text { EHPB180 } \\ \text { ST } & \text { ZOO } & 1 & & & \text { EHPB182 } \\ \text { ST } & \text { ZOO } & 1 & 8 & & \text { EHPB184 }\end{array}$


Tabela 1 (continuação

\begin{tabular}{|c|c|c|c|c|c|c|}
\hline \multirow{2}{*}{ Família/espécie } & \multirow{2}{*}{$\mathrm{CS}$} & \multirow{2}{*}{ SD } & \multicolumn{3}{|c|}{$\mathrm{Ni}$} & \multirow{2}{*}{$\mathrm{N}^{\circ} \mathrm{Col}$} \\
\hline & & & M & Q & $\mathrm{I}$ & \\
\hline Eugenia pruinosa D.Legrand * & $\mathrm{ST}$ & $\mathrm{ZOO}$ & & 1 & 3 & EHPB435 \\
\hline Eugenia subavenia O.Berg & ST & $\mathrm{ZOO}$ & 1 & 1 & & EHPB186 \\
\hline Eugenia convexinervia D.Legrand & ST & $\mathrm{ZOO}$ & & 5 & & EHPB187 \\
\hline Eugenia verticillata (Vell.) Angely & SI & $\mathrm{ZOO}$ & 3 & & & EHPB188 \\
\hline Eugenia $\mathrm{cf}$. kleinii D.Legrand & ST & $\mathrm{ZOO}$ & & & 1 & EHPB174 \\
\hline Marlierea excoriata Mart. & $\mathrm{ST}$ & $\mathrm{ZOO}$ & 1 & 2 & 3 & EHPB189 \\
\hline Marlierea reitzii D.Legrand & ST & $\mathrm{ZOO}$ & & 3 & & EHPB190 \\
\hline Marlierea cf. regeliana O.Berg * & $\mathrm{ST}$ & $\mathrm{ZOO}$ & 1 & 2 & & EHPB183 \\
\hline Myrceugenia myrcioides (Cambess.) O.Berg & $\mathrm{ST}$ & $\mathrm{ZOO}$ & 4 & 1 & 1 & EHPB192 \\
\hline Myrceugenia cf. myrcioides (Cambess.) O.Berg & $\mathrm{ST}$ & $\mathrm{ZOO}$ & 1 & & & EHPB193 \\
\hline Myrcia aethusa (O.Berg) N.Silveira & ST & $\mathrm{ZOO}$ & & 4 & & EHPB194 \\
\hline Myrcia anacardiifolia Gardner & ST & $\mathrm{ZOO}$ & 1 & 1 & & EHPB195 \\
\hline Myrcia macrocarpa DC. & ST & $\mathrm{ZOO}$ & 2 & & & EHPB181 \\
\hline Myrcia multiflora (Lam.) DC. & SI & $\mathrm{ZOO}$ & 3 & 3 & & ЕНРB196 \\
\hline Myrcia tijucensis Kiaersk.* & ST & $\mathrm{ZOO}$ & 2 & 8 & 13 & EHPB197 \\
\hline Neomitranthes capivariensis (Mattos) Mattos * & ST & $\mathrm{ZOO}$ & 2 & & & EHPB203 \\
\hline Myrciaria floribunda (H.West ex Willd.) O.Berg & ST & $\mathrm{ZOO}$ & & & 1 & EHPB199 \\
\hline Myrciaria cf. pallida O.Berg & ST & $\mathrm{ZOO}$ & & & 1 & EHPB198 \\
\hline Plinia rivularis (Cambess.) Rotman & ST & $\mathrm{ZOO}$ & & & 1 & EHPB200 \\
\hline Psidium longipetiolatum D.Legrand & ST & $\mathrm{ZOO}$ & 3 & 1 & & EHPB201 \\
\hline Siphoneugena densiflora O.Berg * & ST & $\mathrm{ZOO}$ & & 1 & & EHPB202 \\
\hline Myrtaceae 1 & - & $\mathrm{ZOO}$ & 1 & & & EHPB205 \\
\hline \multicolumn{7}{|l|}{ Nyctaginaceae } \\
\hline Guapira nitida (Heimerl) Lundell & ST & $\mathrm{ZOO}$ & 3 & 4 & & EHPB102 \\
\hline Guapira opposita (Vell.) Reitz & $\mathrm{ST}$ & $\mathrm{ZOO}$ & 18 & 16 & 8 & EHPB207 \\
\hline \multicolumn{7}{|l|}{ Ochnaceae } \\
\hline Ouratea parviflora (A.DC.) Baill. & ST & $\mathrm{ZOO}$ & & & 1 & ЕНРВ208 \\
\hline Quiina magallano-gomesii Schwacke * & ST & $\mathrm{ZOO}$ & 1 & 1 & & EHPB209 \\
\hline \multicolumn{7}{|l|}{ Olacaceae } \\
\hline Heisteria silvianii Schwacke & $\mathrm{ST}$ & $\mathrm{ZOO}$ & 1 & & 19 & EHPB210 \\
\hline \multicolumn{7}{|l|}{ Oleaceae } \\
\hline Chionanthus filiformis (Vell.) P.S.Green & $\mathrm{ST}$ & $\mathrm{ZOO}$ & & 5 & 1 & EHPB211 \\
\hline \multicolumn{7}{|l|}{ Phyllanthaceae } \\
\hline Savia dictyocarpa Müll.Arg. & $\mathrm{ST}$ & AUT & & & 8 & EHPB212 \\
\hline \multicolumn{7}{|l|}{ Polygonaceae } \\
\hline Coccoloba warmingii Meisn. & SI & $\mathrm{ZOO}$ & 1 & 1 & & ЕНРB213 \\
\hline \multicolumn{7}{|l|}{ Primulaceae } \\
\hline Myrsine gardneriana A.DC. & SI & $\mathrm{ZOO}$ & & 3 & & EHPB214 \\
\hline Myrsine hermogenesii (Jung-Mend. \& Bernacci) M.F.Freitas \& Kin.-Gouv. & ST & $\mathrm{ZOO}$ & 1 & 2 & & EHPB215 \\
\hline
\end{tabular}


Tabela 1 (continuação

Família/espécie

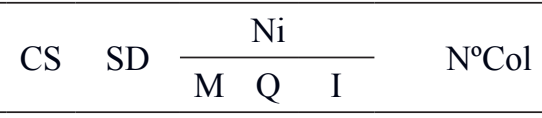

Proteaceae

Roupala sp.

2

EHPB216

Rosaceae

Prunus myrtifolia (L.) Urb.

SI ZOO $\quad 1 \quad 3$

EHPB217

Rubiaceae

Amaioua intermedia Mart.

SI $\quad$ ZOO $5 \quad 5$

EHPB218

Bathysa australis (A.St.-Hil.) K.Schum.

SI AUT 113

EHPB219

Bathysa stipulata (Vell.) C.Presl

SI AUT 2

EHPB113

Cordiera myrciifolia (K.Schum.) C.H.Perss. \& Delprete

$\begin{array}{lllll}\text { ST } & \mathrm{ZOO} & 4 & 8 & 1\end{array}$

EHPB220

Ixora brevifolia Benth.

ST ZOO 2

EHPB94

Posoqueria latifolia (Rudge) Schult.

ST ZOO

EHPB221

Psychotria suterella Müll.Arg.

Rudgea gardenioides (Cham.) Müll.Arg.

Rudgea jasminoides (Cham.) Müll.Arg.

Simira pikia (K.Schum.) Steyerm.

Rubiaceae 1

$\begin{array}{llll}\text { ST } & \mathrm{ZOO} & 1 & 6\end{array}$

EHPB222

ST $\quad \mathrm{ZOO} 1$

EHPB223

$\begin{array}{lllll}\text { ST } & \text { ZOO } & 2 & 24 & 35\end{array}$

EHPB224

ST ANE

EHPB225

1

EHPB226

Rutaceae

Citrus sp. ${ }^{3}$

Esenbeckia grandiflora Mart.

Sabiaceae

Meliosma sellowii Urb.

Salicaceae

Casearia decandra Jacq.

Casearia obliqua Spreng.

$\mathrm{ST}-\mathrm{ZOO}-2 \quad 6$

EHPB230

Casearia sylvestris Sw.

SI $\mathrm{ZOO}-1$ - 3

EHPB231

$\begin{array}{llll}\text { SI } & Z O O & 9 & \text { EHPB232 }\end{array}$

Xylosma glaberrima Sleumer

SI $\quad \mathrm{ZOO} \quad 1$

EHPB233

Sapindaceae

Allophylus petiolulatus Radlk.

$\begin{array}{llll}\text { SI } & \text { ZOO } & 1 & \text { EHPB234 }\end{array}$

Cupania oblongifolia Mart.

SI $\quad Z O O \quad 2 \quad 10$

EHPB235

Cupania vernalis Cambess.

SI $\quad \mathrm{ZOO} \quad 1 \quad 3$

EHPB236

Matayba intermedia Radlk.

Matayba obovata R. Coelho, Souza \& Ferrucci

$\begin{array}{lllll}\text { ST } & Z O O & 2 & 3 & 4\end{array}$

EHPB237

$\begin{array}{lllll}\text { ST } & Z O O & 3 & 1 & \text { EHPB238 }\end{array}$

Sapotaceae

Chrysophyllum flexuosum Mart.

$\begin{array}{llll}\text { ST } & \text { ZOO } & 7 & 3\end{array}$

EHPB239

Diploon cuspidatum (Hoehne) Cronquist

ST $\mathrm{ZOO} \quad 1 \quad 3$

EHPB240

Micropholis crassipedicellata (Mart. \& Eichler) Pierre

$\begin{array}{lllll}\text { ST } & \mathrm{ZOO} & 7 & 3 & 1\end{array}$

EHPB241

Pouteria bullata (S.Moore) Baehni *

ST $\quad$ ZOO $7 \quad 7$

EHPB242 
Tabela 1 (continuação

\begin{tabular}{|c|c|c|c|c|c|c|}
\hline \multirow{2}{*}{ Família/espécie } & \multirow{2}{*}{$\mathrm{CS}$} & \multirow{2}{*}{ SD } & \multicolumn{3}{|c|}{$\mathrm{Ni}$} & \multirow{2}{*}{$\mathrm{N}^{\circ} \mathrm{Col}$} \\
\hline & & & M & Q & I & \\
\hline Pouteria caimito (Ruiz \& Pav.) Radlk. & ST & $\mathrm{ZOO}$ & 3 & & 2 & EHPB243 \\
\hline Pradosia lactescens (Vell.) Radlk. & ST & $\mathrm{ZOO}$ & 1 & 1 & & EHPB244 \\
\hline \multicolumn{7}{|l|}{ Solanaceae } \\
\hline Sessea brasiliensis Toledo & PI & $\mathrm{ZOO}$ & & & 1 & EHPB245 \\
\hline Solanum cinnamomeum Sendtn. & SI & $\mathrm{ZOO}$ & 1 & & & EHPB247 \\
\hline Solanum bullatum Vell. & PI & $\mathrm{ZOO}$ & & & 1 & EHPB248 \\
\hline \multicolumn{7}{|l|}{ Symplocaceae } \\
\hline Symplocos estrellensis Casar. & SI & $\mathrm{ZOO}$ & 4 & 2 & & EHPB249 \\
\hline \multicolumn{7}{|l|}{ Urticaceae } \\
\hline Cecropia hololeuca Miq. & SI & $\mathrm{ZOO}$ & & 2 & & EHPB250 \\
\hline Coussapoa microcarpa (Schott) Rizzini & SI & $\mathrm{ZOO}$ & & 2 & & EHPB251 \\
\hline \multicolumn{7}{|l|}{ Vochysiaceae } \\
\hline Qualea glaziovii Warm. & ST & ANE & & & 1 & EHPB 185 \\
\hline Vochysia magnifica Warm. & ST & ANE & & & 1 & EHPB206 \\
\hline \multicolumn{7}{|l|}{ Winteraceae } \\
\hline Drimys brasiliensis Miers & SI & $\mathrm{ZOO}$ & 3 & 1 & & EHPB98 \\
\hline
\end{tabular}

${ }^{1}$ Espécie inédita (artigo submetido, ainda não publicado) ${ }^{2}$ Espécie nova ${ }^{3}$ Espécie exótica

compreendida entre 6 e 12 m e diminuição da quantidade em direção as maiores e menores alturas (figura 11). Os maiores exemplares amostrados foram Hymenaea courbaril (33 m), no Morro Grande; Aspidosperma olivaceum, Tapirira guianensis e Ocotea catharinensis (24 m), em Itapevi; Beilschmiedia emarginata e Byrsonima ligustrifolia (25 m), em Marsilac.

Categorias sucessionais, síndromes de dispersão e status de conservação das espécies - A representação das espécies em categorias sucessionais na amostragem total (figura 12), mostrou ampla dominância de espécies consideradas secundárias tardias sobre as secundárias iniciais e pioneiras $(72 \%, 24 \%$ e $4 \%$, respectivamente). Considerando as localidades isoladamente, Marsilac e Morro Grande apresentaram percentuais bastante próximos entre si (figura 12). Itapevi, ainda que tenha mantido o padrão geral, contou com uma representação um pouco maior de espécies secundárias iniciais e pioneiras.

Em relação às síndromes de dispersão da amostragem total (figura 13), as espécies zoocóricas constituíram a maioria das espécies $(84 \%)$, seguidas das anemocóricas (11\%) e autocóricas (5\%). Entre as localidades, Morro Grande e Marsilac apresentaram índices muito próximos, enquanto que Itapevi apresentou valores um pouco superiores de espécies anemocóricas e autocóricas.

Segundo as listas oficiais de espécies ameaçadas de extinção, 26 espécies amostradas são consideradas ameaçadas, das quais 18 foram registradas no Morro Grande, 15 em Marsilac e nove em Itapevi (tabela 1).

Esforço amostral e estimativas de riqueza - A figura 14 apresenta a curva de rarefação com 99 randomizações relativas ao acúmulo de espécies, considerando todas as sub-parcelas juntas (60) e as 184 espécies registradas. Em relação às médias de estimativa de riqueza da amostragem total, os resultados variaram de 248 (ACE) a 281 (Jackknife2) espécies. Considerando as localidades isoladamente (figura 15), Morro Grande apresentou maior estimativa de riqueza (181 spp.) e Itapevi a menor (152 spp.).

Similaridade, agrupamento e ordenação - Os resultados da análise de similaridade entre as parcelas de $20 \times 50 \mathrm{~m}$, baseada no Índice Jaccard, estão representados na tabela 3. Comparando-se as localidades, os maiores valores de similaridade foram obtidos entre Marsilac e Morro Grande (0,27 a 0,35) e os menores entre Itapevi e Marsilac $(0,12$ a 0,14$)$. 
Tabela 2. Parâmetros estruturais e de diversidade de três florestas atlânticas maduras da região metropolitana de São Paulo, SP, Brasil. M1 e M2: Marsilac, São Paulo; Q1 e Q2: Reserva Florestal do Morro Grande, Cotia; I1 e I2: Itapevi.

Table 2. Parameters of structure and diversity of three mature Atlantic Forests from São Paulo metropolitan area, São Paulo State, Brazil. M: Marsilac, São Paulo; Q: Morro Grande Forest Reserve, Cotia; I: Itapevi.

\begin{tabular}{lcccccccccc}
\hline & M1 & M2 & $\begin{array}{c}\text { Total } \\
(\mathrm{M})\end{array}$ & Q1 & Q2 & Total (Q) & I1 & I2 & Total (I) & Total \\
\hline $\mathrm{N}^{\text {o ind. amostrados }}$ & 138 & 168 & 306 & 161 & 191 & 352 & 157 & 128 & 285 & 943 \\
$\mathrm{~N}^{\text {o de espécies }}$ & 64 & 75 & 103 & 69 & 59 & 97 & 67 & 45 & 91 & 184 \\
$\mathrm{~N}^{\text {o de famílias }}$ & 23 & 28 & 36 & 28 & 25 & 35 & 34 & 24 & 37 & 50 \\
Densidade & 1.380 & 1.680 & 1.530 & 1.610 & 1.910 & 1.760 & 1.570 & 1.280 & 1.425 & 1.572 \\
Área Basal & 50 & 48,5 & 49,3 & 39,5 & 49,5 & 44,5 & 52,1 & 36 & 44,5 & 46,1 \\
Shannon & 3,94 & 4,03 & 4,29 & 3,9 & 3,6 & 4,02 & 3,91 & 3,21 & 3,99 & 4,62 \\
Equabilidade & 0,95 & 0,93 & 0,92 & 0,92 & 0,88 & 0,88 & 0,93 & 0,85 & 0,89 & 0,88 \\
\hline
\end{tabular}

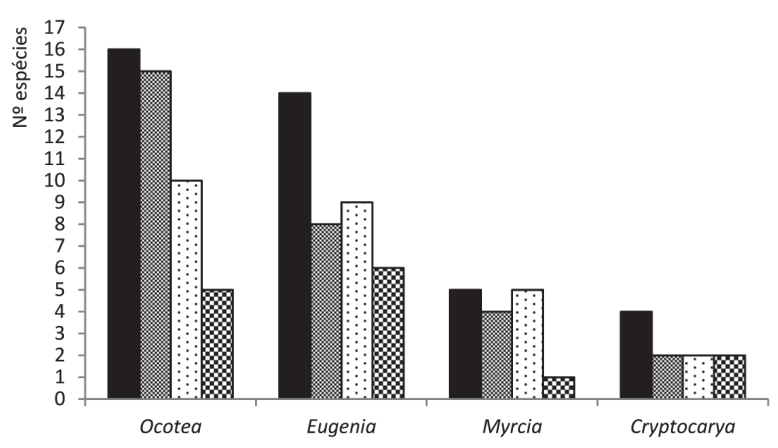

Figura 7. Gêneros mais ricos em três florestas atlânticas maduras da região metropolitana de São Paulo, SP, Brasil. [ Marsilac, São Paulo; $\square$ Reserva Florestal do Morro Grande, Cotia; Itapevi, $\square$ Total.

Figure 7. The most richness genera in three mature Atlantic Forests from São Paulo metropolitan area, São Paulo State, Brazil. [ Marsilac, São Paulo; -1 Morro Grande Forest Reserve, Cotia; 因 Itapevi, $\square$ Total

Itapevi apresentou maior similaridade com Morro Grande, embora com valores relativamente baixos $(0,16$ a 0,23$)$.

A análise de agrupamento UPGMA (figura 16) entre as parcelas de $20 \times 50 \mathrm{~m}$ (índice de correlação cofenética 0,95 ) resultou na formação de dois grupos: o grupo 1, formado pelas duas parcelas de Itapevi, e o grupo 2, formado pelo conjunto das parcelas de Marsilac e do Morro Grande. Esse segundo grupo se dividiu em dois subgrupos, um formado por M1 e M2 (grupo 3) e a outra por Q1 e Q2 (grupo 4). A análise de agrupamento UPGMA (figura 17) realizada entre as parcelas de $10 \times 10$ $\mathrm{m}$ (índice de correlação cofenética 0,67 ) também resultou na formação de um grupo composto exclusivamente pelas parcelas de Itapevi e outro por uma mistura entre as parcelas do Morro Grande e Marsilac.
A análise de ordenação DCA (figura 18) entre as parcelas de $20 \times 50 \mathrm{~m}$ distribuiu as localidades ao longo de um eixo principal (eixo 1 com autovalor de 0,62 e comprimento 3,40 sd) com as parcelas M2 e M1 em um extremo e I2 e I1 no outro extremo do eixo. As parcelas Q1 e Q2 situaram-se em posição intermediária no eixo 1, embora muito mais próximos de M1 e M2. O eixo 2 (autovalor de 0,26 e comprimento de 1,76 sd) isolou a parcela Q1 de Q2, cada uma em um extremo e concentrou as demais parcelas (M1, M2, I1 e I2) no centro do gráfico. A análise de ordenação entre as parcelas de $10 \times 10 \mathrm{~m}$ manteve o padrão geral da análise anterior, embora se observe maior mistura entre as localidades ao longo do eixo 1 (autovalor de 0,67 e comprimento de 5,47 sd), especialmente entre Morro Grande e Marsilac (figura 19). No eixo 2 (autovalor de 0,45 e comprimento de $4,16 \mathrm{sd}$ ) também observa-se maior mistura entre as localidades em relação a análise anterior.

\section{Discussão}

O índice de Shannon obtido para as florestas amostradas neste trabalho $(4,62)$, considerando-se todas as parcelas juntas, foi um dos maiores para a região metropolitana de São Paulo, abaixo apenas dos 4,75 obtido por Catharino et al. (2006) em florestas do Morro Grande, e também um dos mais altos para o Estado de São Paulo. Apesar de se tratar de uma amostragem que possui alguma variação interna, devido à maior amplitude geográfica que os demais estudos realizados na região, os altos valores aqui obtidos caracterizam a diversidade das florestas maduras que podem ocorrer na região metropolitana de São Paulo (RMSP). Mesmo considerando as localidades separadamente, os valores de diversidade também são altos (3,99 a 4,29), abaixo apenas, na 
Tabela 3. Matriz de similaridade de Jaccard entre as seis parcelas amostradas $(20 \times 50 \mathrm{~m})$ em três florestas atlânticas maduras da região metropolitana de São Paulo, SP, Brasil. M1 e M2: Marsilac, São Paulo; Q1 e Q2: Reserva Florestal do Morro Grande, Cotia; I1 e 12: Itapevi.

Table 3. Jaccard similarity matrix between the six plots $(20 \times 50 \mathrm{~m})$ of three mature Atlantic Forests from São Paulo metropolitan area, São Paulo State, Brazil. M1 and M2: Marsilac, São Paulo; Q1 and Q2: Morro Grande Forest Reserve, Cotia; I1 and I2: Itapevi.

\begin{tabular}{lllllll}
\hline $\mathrm{I} 1$ & & & & & \\
0,23 & $\mathrm{I} 2$ & & & & \\
0,20 & 0,17 & $\mathrm{Q} 1$ & & & \\
$0, \overline{2} \overline{3}$ & $\hat{0}, \overline{2} \overline{1}$ & $0, \overline{3} \overline{2}$ & $\overline{\mathrm{Q}} \mathbf{2}$ & & \\
0,15 & 0,12 & 0,28 & 0,33 & $\mathrm{M} 1$ & \\
0,14 & 0,14 & 0,36 & 0,35 & 0,33 & $\mathrm{M} 2$ \\
\hline
\end{tabular}

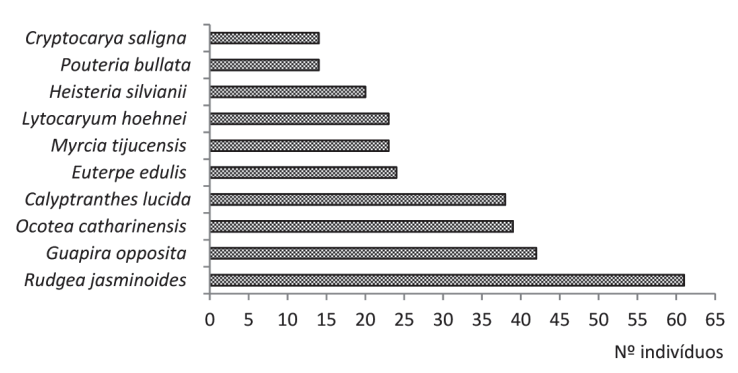

Figura 8. Espécies arbóreas com maiores valores de densidade na amostragem total de três florestas atlânticas maduras da região metropolitana de São Paulo, SP, Brasil (Marsilac, São Paulo; Reserva Florestal do Morro Grande, Cotia; Itapevi).

Figure 8. Highest values of arboreal species density in total sample of three mature Atlantic Forests from São Paulo metropolitan area, São Paulo State, Brazil (Marsilac, São Paulo; Morro Grande Forest Reserve, Cotia; Itapevi).

RMSP, da floresta madura amostrada por Catharino et al. (2006) também no Morro Grande (4,53).

As famílias mais ricas em espécies na amostragem total (Myrtaceae, Lauraceae, Rubiaceae e Fabaceae) são usualmente bem representadas nas florestas da RMSP, já que são citadas como as de maior riqueza nos trabalhos de Vuono (1985), Grombone et al. (1990), Gandolfi (1991), Gomes (1992), Baitello et al. (1993), Cardoso-Leite (1995), Aragaki (1997), Garcia \& Pirani (2001), Arzolla (2002), Catharino et al. (2006), Ogata \& Gomes (2006) e Rosário (2010). Segundo estimativa realizada por Arzolla et al. (2011), essas mesmas famílias são responsáveis por $34 \%$ a $46 \%$ do total de espécies em levantamentos da RMSP. Além dessas, Euphorbiaceae também é uma família que apresenta alta riqueza em alguns trabalhos da região (Gandolfi 1991, Aragaki 1997, Garcia \& Pirani 2001, Arzolla 2002), diferentemente de Sapotaceae, família geralmente associada a florestas ombrófilas mais desenvolvidas. Em relação ao número de indivíduos por família, Lauraceae e Myrtaceae mantiveram-se como as mais abundantes, enquanto que Euphorbiaceae e Fabaceae foram substituídas por Arecaceae e Nyctaginaceae, em função da alta densidade de Euterpe edulis, Lytocaryum hoehnei e Guapira opposita.

Os gêneros Ocotea e Eugenia, os dois mais ricos na amostragem total (16 e 14 spp., respectivamente), também estão entre os mais representativos em muitos estudos realizados na Província Atlântica (Catharino et al. 2006). No entanto, chama atenção a alta contribuição desses dois gêneros, que somados

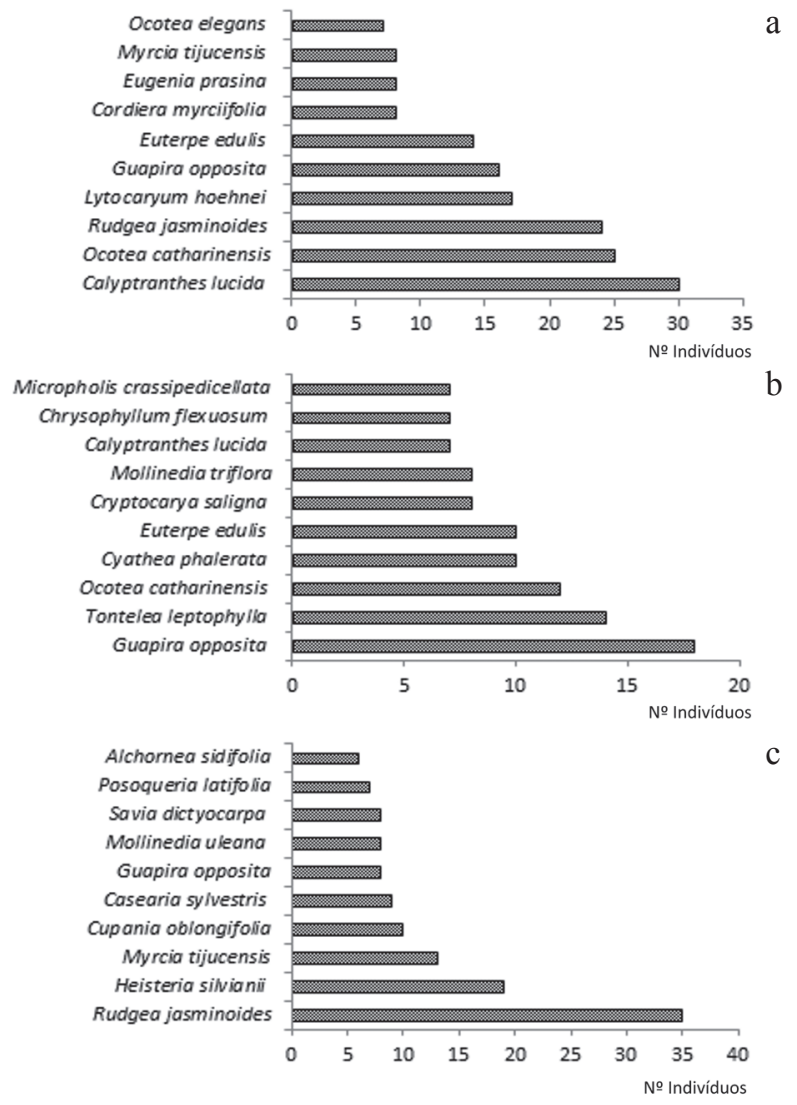

Figura 9. Espécies arbóreas amostradas com maiores valores de densidade em três florestas atlânticas maduras da região metropolitana de São Paulo, SP, Brasil. a. Reserva Florestal do Morro Grande, Cotia; b. Marsilac, São Paulo; c. Itapevi.

Figure 9. Highest values of arboreal species density of three mature Atlantic Forests from São Paulo metropolitan area, São Paulo State, Brazil. a. Morro Grande Forest Reserve, Cotia; b. Marsilac, São Paulo; c. Itapevi. 
representaram $27,5 \%$ de todas as espécies amostradas especialmente em Marsilac e Morro Grande, com cerca de $20 \%$ das espécies. Em florestas secundárias de Guarulhos e de Cotia estudadas por Gandolfi et al. (1995) e Ogata \& Gomes (2006), respectivamente, Ocotea e Eugenia representaram, em ambos os estudos, apenas $8 \%$ das espécies. Em uma floresta em estágio inicial de regeneração no Morro Grande, Rosário (2010) obteve 7\% de Ocotea e Eugenia. Ainda que Itapevi tenha apresentado valores menores, esses dados sugerem que a alta riqueza e altos percentuais de espécies de Ocotea e Eugenia possam estar associados a florestas mais desenvolvidas na RMSP.

Em relação às espécies, as duas que apresentaram os maiores valores de densidade (Rudgea jasminoides e Guapira opposita) também estão entre as mais abundantes em alguns estudos da região (CardosoLeite 1995, Catharino et al. 2006). Por outro lado, outras espécies que apresentaram valores expressivos de densidade foram pouco amostradas em trabalhos da RMSP, como Calyptranthes lucida, Chrysophyllum flexuosum, Cryptocarya saligna, Cyathea phalerata, Euterpe edulis, Heisteria silvianii, Lytocaryum hoehnei, Myrcia tijucensis, Ocotea catharinensis, Pouteria bullata e Tontelea leptophylla. A baixa densidade ou até mesmo a ausência destas espécies em grande parte das florestas já estudadas na RMSP deve estar relacionada ao fato de que muitos desses trabalhos tenham sido realizados em matas degradadas ou jovens. De fato, apenas as poucas florestas maduras já estudadas na RMSP (Arzolla 2002, Catharino et al. 2006, Rosário 2010) apresentaram resultados similares. Essa diferença entre florestas jovens e maduras está relacionada ao processo de substituição

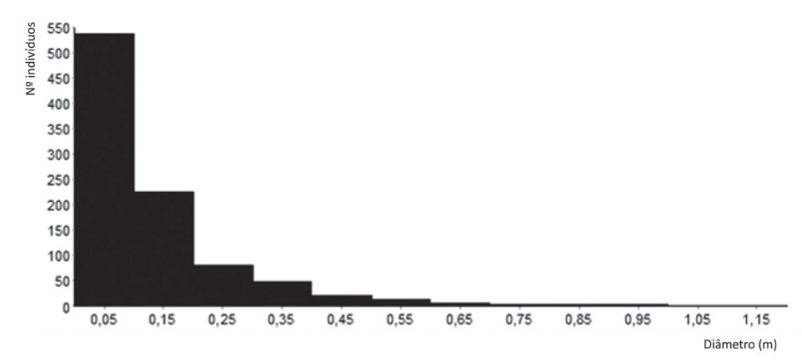

Figura 10. Representação dos indivíduos arbóreos em classes de diâmetro $(0,10 \mathrm{~m})$ de florestas atlânticas maduras amostradas na região metropolitana de São Paulo, SP, Brasil (Reserva Florestal do Morro Grande, Cotia; Marsilac, São Paulo; Itapevi).

Figure 10. Representation by diameter classes $(0,10 \mathrm{~m})$ of trees in mature Atlantic Forests from São Paulo metropolitan area, São Paulo State, Brazil (Marsilac, São Paulo; Morro Grande Forest Reserve, Cotia; Itapevi). de espécies que ocorre ao longo do amadurecimento de uma comunidade florestal, como já documentado em diversos estudos (Budowski 1963, 1965, 1970, Guariguata \& Ostertag 2001, entre outros). Outro aspecto que pode explicar a diferença na composição e densidade de espécies entre este trabalho e outros realizados em matas secundárias ou jovens, é a baixa conectividade entre estas e matas maduras, fator que dificulta a chegada de propágulos de árvores climácicas às florestas secundárias da região.

Outra característica de florestas mais desenvolvidas é apresentar uma distribuição diamétrica com grande amplitude e padrão de curva "J" invertido, com maior quantidade de indivíduos com diâmetros pequenos e progressiva diminuição da quantidade de árvores com diâmetros maiores. A presença de algumas árvores secundárias tardias com diâmetro elevado (próximo a $1 \mathrm{~m}$ ) é característica marcante de florestas maduras, aspecto também observado por Rosário (2010) em florestas do Morro Grande. Este autor amostrou árvores com diâmetros máximos de 43 a $66 \mathrm{~cm}$ em florestas em estágio inicial e médio de regeneração, e de $86,3 \mathrm{~cm}$ (Tachigali denudata) em um trecho de florestas madura (além de uma Coussapoa microcarpa de $197 \mathrm{~cm}$, espécie considerada secundária inicial). Da mesma forma, Arzolla (2002) e Baitello et al. (1993) amostraram árvores com altos valores de diâmetro em florestas maduras da Serra da Cantareira, com diâmetro máximo de $107 \mathrm{~cm}$ (Beilschmiedia emarginata) e 121 $\mathrm{cm}$ (Euplassa cantareirae), respectivamente.

Em relação à estratificação florestal, não se observou a existência de padrões muito claros, possivelmente pela presença de múltiplos estratos arbóreos de difícil reconhecimento, complexidade

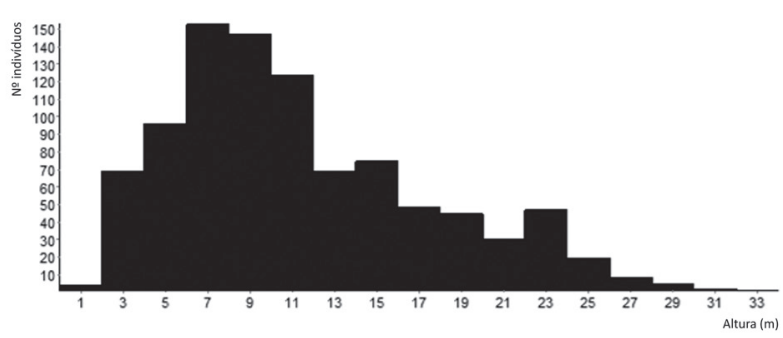

Figura 11. Representação dos indivíduos arbóreos em classes de alturas ( $2 \mathrm{~m}$ ) de florestas atlânticas maduras amostradas na região metropolitana de São Paulo, SP, Brasil (Reserva Florestal do Morro Grande, Cotia; Marsilac, São Paulo; Itapevi).

Figure 11. Representation by height classes $(2 \mathrm{~m})$ of trees of mature Atlantic Forests from São Paulo metropolitan area, São Paulo State, Brazil (Marsilac, São Paulo; Morro Grande Forest Reserve, Cotia; Itapevi). 
também característica de florestas tropicais maduras. Observa-se apenas a ocorrência de uma concentração maior de indivíduos na faixa compreendida entre 6 e $12 \mathrm{~m}$, explicada pela sobreposição de habitats de espécies típicas de sub-bosque com os de indivíduos jovens de espécies secundárias tardias (transientes). $\mathrm{O}$ sub-bosque, considerado aqui como tudo que não atinge o dossel, é dominado por Myrtaceae (principalmente pela diversidade, embora algumas espécies tenham apresentado densidade expressiva, como Calyptranthes lucida e Myrcia tijucencis), alta densidade de algumas espécies de Rubiaceae (Rudgea jasminoides e Psychotria suterella, esta última mais frequente em diâmetros menores), Arecaceae (Euterpe edulis e Lytocaryum hoehnei, além de Geonoma spp. em diâmetros menores), Nyctaginaceae (Guapira opposita e em menor quantidade Guapira nitida), Monimiaceae (Mollinedia boracensis, Mollinedia triflora Mollinedia uleana) e Cyatheaceae (Cyathea delgadii, Cyathea dichromatolepis e Cyathea phalerata).

O dossel, tal como o sub-bosque, configura-se como um estrato heterogêneo, tanto pela elevada riqueza de espécies quanto pela variação de altura (20-30 m), frequentemente interrompido por grandes clareiras causadas pela queda de árvores ou por indivíduos emergentes que podem atingir $40 \mathrm{~m}$. Apesar de ser composto por inúmeras espécies, observa-se a predominância de espécies secundárias tardias de

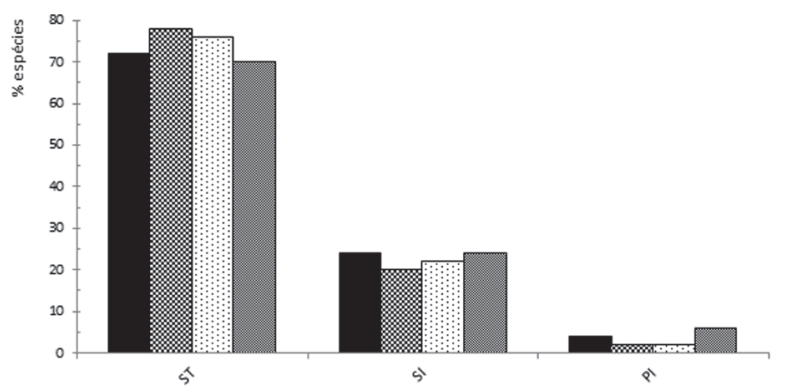

Figura 12. Porcentagem de espécies arbóreas amostradas, segundo categoria sucessional, em três florestas maduras da região metropolitana de São Paulo, SP, Brasil. PI: espécie pioneira; SI: espécie secundária inicial; ST: espécie secundária tardia. Marsilac, São Paulo; \% Reserva Florestal do Morro Grande, Cotia; Itapevi, $\square$ Total.

Figure 12. Percentage of arboreal species sampled according to the successional category of three mature Atlantic Forests from São Paulo metropolitan area, São Paulo State, Brazil PI: pioneer species; SI: early secondary species; ST: late secondary species. 1 Marsilac, São Paulo; : Morro Grande Forest Reserve, Cotia; Itapevi, Total.
Lauraceae (Beilschmiedia emarginata, Cryptocarya mandioccana, C. saligna, Ocotea catharinensis, $O$. elegans e O. venulosa) e Sapotaceae (Micropholis crassipedicelata, Pouteria bullata e P. caimito). Naturalmente, outras famílias são comuns nos estratos superiores, como Fabaceae, com representantes típicos de florestas maduras, como Copaifera trapezifolia, Hymemaea courbaril, Myrocarpus frondosus, Tachigali denudata; além de Apocynaceae (Aspidosperma spp.), Lecythidaceae (Cariniana spp.) e Elaeocarpaceae (Sloanea guianensis e S. lasiocoma).

Dentre as principais espécies tardias do dossel das florestas maduras da região, destaca-se Ocotea catharinensis, devido à alta densidade nos mais variados diâmetros e alturas, chegando a mais de $30 \mathrm{~m}$ de altura, e a enorme capacidade de germinação e manutenção de expressivos bancos de plântulas sob a sombra. Tal característica proporciona o desenvolvimento contínuo das populações e a manutenção da dominância dessa espécie, razões pelas quais possa ser considerada como uma das espécies climácicas mais típicas das matas maduras da região metropolitana de São Paulo. Corroborando essa observação, Reitz et al. (1979), relataram que essa espécie era, sem dúvida, a árvore mais importante da zona da mata pluvial da encosta atlântica, chegando a representar $1 / 3$ do volume de todas as madeiras existentes num hectare, ocupando quase toda a região da costa atlântica, sendo abundante ao longo das encostas e chapadas - principalmente entre $300 \mathrm{e}$

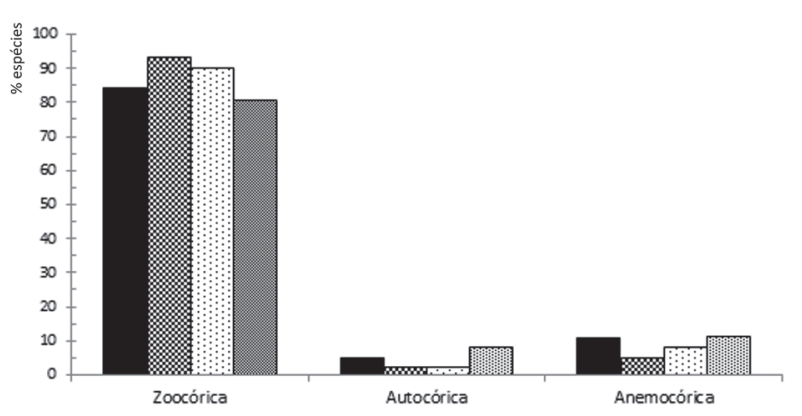

Figura 13. Porcentagem de espécies arbóreas amostradas, segundo síndromes de dispersão, de três florestas atlânticas maduras da região metropolitana de São Paulo, SP, Brasil.

Marsilac, São Paulo; $\boldsymbol{\otimes}$ Reserva Florestal do Morro Grande, Cotia; Itapevi, Total.

Figure 13. Percentage of arboreal species according to dispersal syndrome of three mature Atlantic Forests from São Paulo metropolitan area, São Paulo State, Brazil. Marsilac, São Paulo; $\$$ Morro Grande Forest Reserve, Cotia; Total. 
700 metros de altitude. Além disso, a madeira usada na construção das casas coloniais paulistanas era seguidamente a canela preta (Loureiro 1981), nome popular dessa espécie. Nesse sentido, a presença de O. catharinensis em florestas da região, especialmente de indivíduos de grande porte, são fortes indicativos de se estar diante de uma mata madura que tenha sofrido pouca interferência humana.

$\mathrm{O}$ alto grau de maturidade das florestas amostradas pode ser observado nos expressivos porcentuais de espécies secundárias tardias. Deve ser ressaltado, no entanto, que não há consenso na literatura sobre a categoria sucessional de algumas espécies ou mesmo não há informações disponíveis, de forma que muitas foram classificadas baseadas em observações pessoais - sendo necessários mais estudos para consolidar o conhecimento sobre a biologia dessas espécies. Na classificação realizada, Itapevi apresentou uma participação um pouco maior de espécies secundárias iniciais, possivelmente pela degradação causada pelo incêndio da década de 1960. Ainda assim, boa parte de sua estrutura primária permaneceu, com espécies climácicas dominando o dossel, como Aspidosperma olivaceum, Cariniania estrellensis, Cryptocarya mandioccana, Heisteria silvianii, Ocotea catharinensis, Savia dictyocarpa e Sloanea lasiocoma.

A predominância de espécies zoocóricas também é um aspecto relacionado a florestas mais desenvolvidas (Budowski 1963, 1965, 1970), embora faltem dados

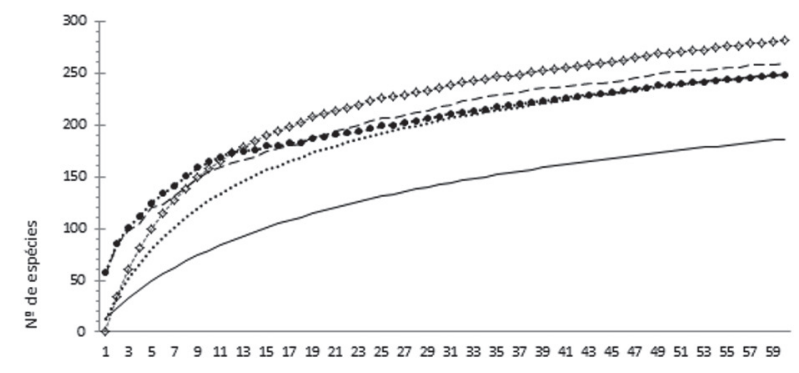

Figura 14. Riqueza de espécies observada S (est) e estimada (ACE, Chao1, Jackknife1, Jackknife2), considerando todas as 60 parcelas $(10 \times 10 \mathrm{~m})$ amostradas em três florestas atlânticas maduras da região metropolitana de São Paulo, SP, Brasil (Marsilac, São Paulo; Reserva Florestal do Morro Grande, Cotia; Itapevi). S(est), ....... ACE, --- Chao 1, ........ Jackknife 1, — Jackknife 2.

Figure 14. Observed species richness $\mathrm{S}$ (est) and estimated richness (ACE, Chao1, Jackknife1, Jackknife2) of three mature Atlantic Forests from São Paulo metropolitan area, São Paulo State, Brazil (Marsilac, São Paulo; Morro Grande Forest Reserve, Cotia; Itapevi), considering all the 60 plots $(10 \times 10 \mathrm{~m})$. — S(est), ........ ACE, --- Chao 1, ........ Jackknife 1, ↔ Jackknife 2. quantitativos que demonstrem isso. Dentre os trabalhos já realizados na região metropolitana de São Paulo, poucos são os que apresentaram dados sobre síndrome de dispersão das espécies. Catharino et al. (2006) obteve porcentuais altos de espécies zoocóricas no Morro Grande, tanto em trechos de florestas maduras (77\%-89\%) quanto em estágio médio/avançado de regeneração (83\%-84\%). Arzolla (2011), estudando clareiras antrópicas na Serra da Cantareira (SP) obteve $71 \%$ de espécies zoocóricas e $22 \%$ anemocóricas. Ainda que faltem mais estudos, esses dados indicam que podem ser sutis as variações nos percentuais de síndrome de dispersão de espécies entre florestas da RMSP em estágios sucessionais diferentes.

Aspecto que deve ser destacado foi a ocorrência de uma grande quantidade de espécies ameaçadas

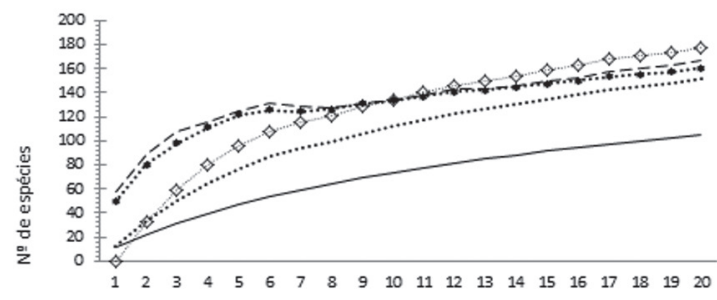

a
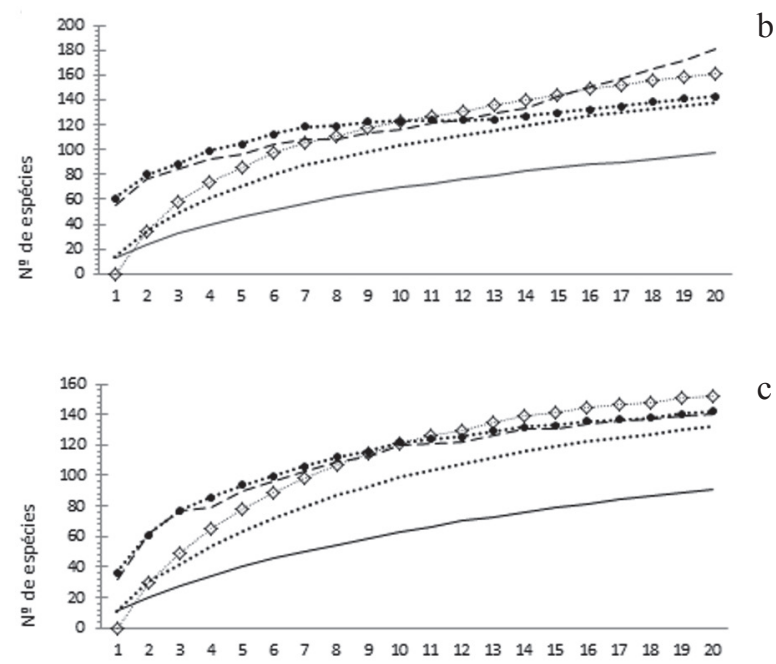

Figura 15. Riqueza de espécies observada S (est) e curvas de riqueza estimadas (ACE, Chao1, Jackknife1, Jackknife2) de amostragem realizada em três florestas maduras da região metropolitana de São Paulo, SP, Brasil. a. Marsilac, São Paulo; b. Reserva Florestal do Morro Grande, Cotia; c. Itapevi. S(est), ....... ACE, --- Chao 1, ........ Jackknife 1, - - Jackknife 2.

Figure 15. Observed species richness $\mathrm{S}$ (est) and estimated richness (ACE, Chao1, Jackknife1, Jackknife2) of three mature forests from São Paulo metropolitan area, São Paulo State, Brazil. a. Marsilac, São Paulo; b. Morro Grande Forest Reserve, Cotia; c. Itapevi. - S(est), ....... ACE, --- Chao 1, ........ Jackknife $1, \ldots$ Jackknife 2. 
de extinção (26 spp.), pouco amostradas ou mesmo inéditas em trabalhos sobre a flora arbórea da RMSP. Em relação àquelas que sofrem algum risco de extinção, não só foram amostradas muitas espécies, como também foram registradas populações expressivas de algumas delas, como Euterpe edulis, Myrcia tijucensis, Ocotea catharinensis, Pouteria bullata e Tontelea leptophylla. Merece destaque também a descoberta de uma espécie nova de Lauraceae, uma árvore de $29 \mathrm{~m}$ coletada com botões florais na parcela Q1 do Morro Grande, e posteriormente recoletada com flores em um remanescente primitivo em Marsilac.

Não foram encontradas em nenhum outro trabalho publicado para a RMSP Calyptranthes dryadica, Copaifera lucens, Cryptocarya micrantha, Duguetia salicifolia, Maytenus cestrifolia, Mollinedia boracensis, Neomitranthes capivariensis, Ocotea leucoxylon, Pera heteranthera, Protium kleinii, Simira pikia, Sloanea lasiocoma e Tontelea leptophylla. Dentre essas, destacam-se Neomitranthes capivariensis, planta considerada extinta no Estado de São Paulo (SMA 2004), conhecida apenas pela coleta tipo feita há mais de 100 anos em Capivari, interior do Estado, e desde então, nunca mais coletada (Martinelli \& Moraes 2013); Protium kleinii, coletado apenas uma vez na capital de São Paulo, há mais de meio século (Lima \& Pirani 2005). Além desses registros, diversas espécies amostradas apresentam ocorrência rara em trabalhos publicados para a RMSP, como Aniba firmula, Aniba viridis, Buchenavia kleinii, Cinnamomum hirsutum, Copaifera trapezifolia, Eugenia beaurepaireana,

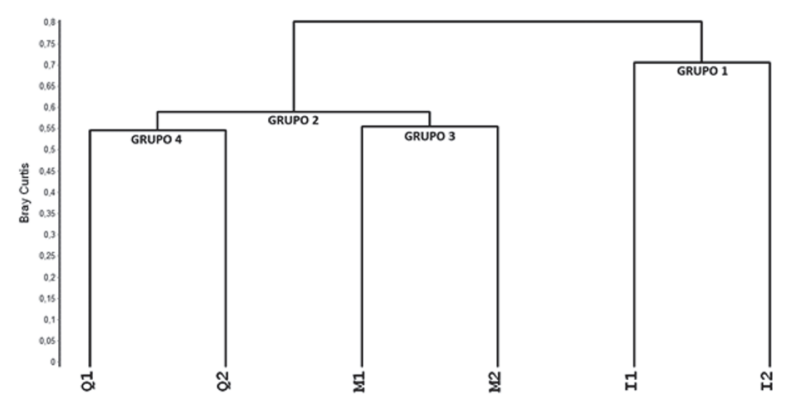

Figura 16. Dendrograma UPGMA entre seis parcelas de $20 \times 50$ $\mathrm{m}$ de três florestas atlânticas maduras da região metropolitana de São Paulo (SP, Brasil), com a utilização do coeficiente de Bray Curtis. Q1 e Q2: Reserva Florestal do Morro Grande, Cotia; M1 e M2: Marsilac, São Paulo; I1 e 12: Itapevi.

Figure 16. Cluster analysis (UPGMA) between the six plots $(20 \times 50 \mathrm{~m})$ of three mature Atlantic Forests from São Paulo metropolitan area (São Paulo State, Brazil), using Bray Curtis coefficient. M1 and M2: Marsilac, São Paulo; Q1 and Q2: Morro Grande Forest Reserve, Cotia; I1 and I2: Itapevi.
Eugenia copacabanensis, Eugenia pruinosa, Ilex theezans, Inga lenticellata, Marlierea reitzii, Myrcia aethusa, Myrsine hermogenesii, Ocotea daphnifolia, Ocotea odorifera, Plinia rivularis, Pradosia lactescens, Psidium longipetiolatum, Qualea glaziovii, Quiina magallano-gomesii, Trichilia lepidota, Virola bicuhyba e Xylopia langsdorfiana. Todas essas espécies deveriam ser alvo de programas de coleta de sementes e de plantio de mudas em florestas secundárias da RMSP, contribuindo assim com o enriquecimento das matas da região e com a preservação de espécies ameaçadas e/ou raras.

A alta riqueza dessas florestas e a presença de grande quantidade de espécies raras, por outro lado, são fatores que dificultam a estabilização da curva de acumulação de espécies, fato observado nas análises realizadas. No entanto, os formatos das curvas revelam uma tendência à estabilização, com incremento maior de espécies nas parcelas iniciais (até a amostra 20, aproximadamente) e a sucessiva diminuição ao longo das 40 parcelas seguintes. Em relação às estimativas de riqueza na amostragem total, pode-se dizer que foram registradas de $66 \%$ a $75 \%$ das espécies arbóreas das florestas maduras da RMSP e de $53 \%$ a $70 \%$ da riqueza arbórea de cada localidade.

Os resultados obtidos pelas análises de similaridade revelaram a existência de grande afinidade florística entre Morro Grande e Marsilac, os quais formaram, inclusive, um grupo misto na análise de agrupamento entre as parcelas de $10 \times 10 \mathrm{~m}$. Por outro lado, as parcelas de Itapevi apresentaram baixa similaridade com as demais localidades e se mantiveram isoladas nas análises de agrupamento, formando um grupo único. Os gráficos de ordenação mostraram a presença de uma variação florística contínua ao longo do eixo 1 , com as parcelas de Marsilac em um extremo e as de Itapevi em outro, e Morro Grande em posição intermediária, embora mais próximo de Marsilac. O comprimento do eixo $1(3,4 \mathrm{sd})$ da DCA entre as parcelas de $20 \times 50 \mathrm{~m}$ ficou um pouco abaixo de 4 sd e quer dizer que os resultados da ordenação não necessariamente representariam uma variação real dos dados de diversidade beta (Oksanen 2011). No entanto, o comprimento do eixo 1 da DCA entre as sub-parcelas de $10 \times 10 \mathrm{~m}$ apresentou comprimento $(5,47 \mathrm{sd})$ bem superior a $4 \mathrm{sd}$, o que significa que as espécies representadas em uma extremidade do eixo, estão praticamente ausentes na outra (Oksanen 2011). Dessa forma, algumas sub-parcelas de Itapevi apresentaram composição de espécies totalmente diferente de algumas sub-parcelas de Marsilac e Morro 
Grande. Esses resultados confirmam a presença de um gradiente florístico ao longo dos planaltos da RMSP, entre as localidades estudadas, no mesmo sentido em que se distancia do oceano e se adentra no interior do Estado de São Paulo. Essa variação é observada, de forma sutil, entre Marsilac e Morro Grande e mais acentuadamente, entre Morro Grande e Itapevi.

Interessante observar que a distância entre Morro Grande e Marsilac (34 km) é 1,6 vezes superior a distância entre Morro Grande e Itapevi $(21 \mathrm{~km})$ e que a altitude das florestas amostradas no Morro Grande é a mesma de Itapevi (950-975 m), 200 metros acima de Marsilac (750-775 m). Dessa forma, nem a proximidade geográfica e muito menos a altitude poderiam ser os fatores causadores das diferenças florísticas observadas. Por outro lado esses aspectos reforçam a existência de um bloco florístico mais homogêneo na região compreendida entre Marsilac e Morro Grande - embora também haja particularidades florísticas em cada localidade.

Os solos tampouco parecem explicar as variações florísticas observadas. Apesar de Morro Grande e Marsilac situarem-se sobre cambissolos háplicos e Itapevi em argissolos vermelho-amarelos, ambos podem ser considerados distróficos e ácidos. Ainda assim, todas as parcelas possuem árvores frondosas, indicando que não há restrição edáfica para o desenvolvimento das comunidades florestais estudadas. Tudo indica que a variação florística deva ser provocada por mudanças nas condições climáticas existentes entre Morro Grande/Marsilac e Itapevi, tal como apontado por Catharino (2006) e Durigan et al. (2008) em estudos realizados no Planalto de Ibiúna (SP).

Considerando dados recentes, verifica-se que a temperatura média no inverno em Itapevi é de aproximadamente $1,5^{\circ} \mathrm{C}$ mais quente que a média do Morro Grande e as médias pluviométricas de Itapevi no inverno são um pouco menores que as médias do Morro Grande (de até $10 \mathrm{~mm}$, em agosto). Essa pequena variação climática provoca um inverno um pouco mais seco em Itapevi do que nas demais localidades estudadas, com pelo menos dois meses de restrição hídrica, tal como evidenciam os gráficos de balanço hídrico. Essa redução na disponibilidade de água deve ser um dos principais fatores responsáveis pelas variações florísticas observadas.

Essa suposição é reforçada pela presença de espécies comumente associadas às florestas estacionais semidecíduas em Itapevi (Oliveira 2006, Silveira 2009), fisionomia que domina a paisagem no interior do Estado de São Paulo e típica de ambientes sujeitos a um déficit hídrico mais acentuado, tais como Aspidosperma polyneuron, Cassia ferruginea, Ocotea corymbosa, Savia dictyocarpa e Sloanea lasiocoma. Dentre essas, destaca-se a presença da

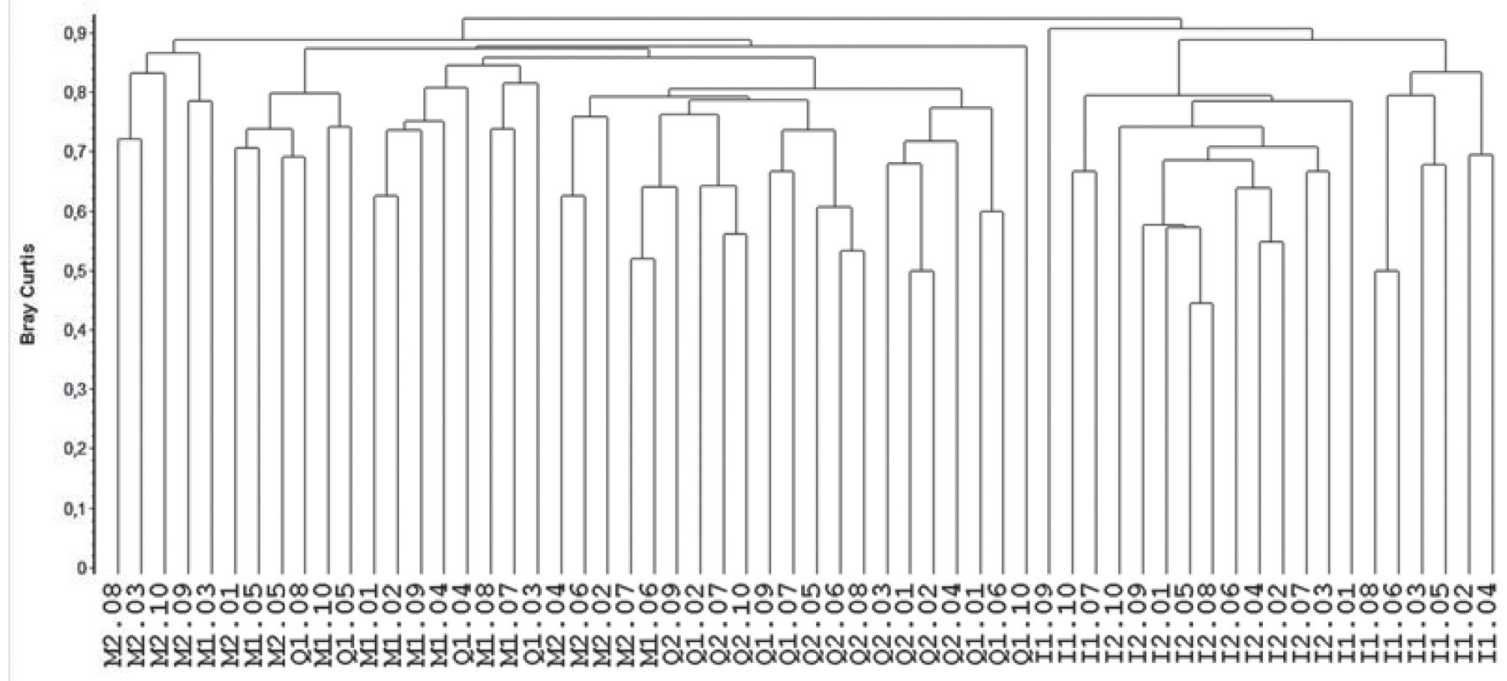

Figura 17. Dendrograma UPGMA entre 60 parcelas $(10 \times 10 \mathrm{~m})$ amostradas em três florestas atlânticas maduras da região metropolitana de São Paulo (SP, Brasil), com a utilização do coeficiente de Bray Curtis. M1 e M2: Marsilac, São Paulo; Q1 e Q2: Reserva Florestal do Morro Grande, Cotia; I1 e 12: Itapevi.

Figure 17. Cluster analysis (UPGMA) between the sixty plots $(10 \times 10 \mathrm{~m})$ sampled in three mature Atlantic Forests from São Paulo metropolitan area (São Paulo State, Brazil), using Bray Curtis coefficient. M1 and M2: Marsilac, São Paulo; Q1 and Q2: Morro Grande Forest Reserve, Cotia; I1 and I2: Itapevi. 
peroba-rosa (Aspidosperma polyneuron), espécie muito amostrada em levantamentos de florestas estacionais semidecíduas do interior do Estado de São Paulo (Rozza 1997, Durigan et al. 2000, Fonseca \& Rodrigues 2000, Gorenstein 2002). Apesar de ter sido amostrado um único indivíduo jovem, a alguns metros fora da parcela I1 havia um indivíduo adulto ocupando o dossel da floresta. Da mesma forma que a peroba-rosa, Savia dictyocarpa também está presente entre as principais espécies em trabalhos de florestas estacionais semidecíduas, tendo sido amostrado em Itapevi um indivíduo adulto e alguns jovens. Cabe apontar que essas duas espécies também foram amostradas na Serra da Cantareira por Arzolla (2002), reforçando a suposição de que essa região, situada mais ao norte da RMSP, aparenta maior semelhança com as matas do interior paulista do que florestas localizadas mais ao sul da região metropolitana.

Tal como as espécies, algumas famílias mais relacionadas às florestas estacionais semidecíduas também foram mais representadas em Itapevi, do que em Marsilac e no Morro Grande, como Apocynaceae, Euphorbiaceae e Meliaceae. Além disso, a porcentagem de espécies anemocóricas também foi comparativamente maior em Itapevi, característica relacionada a florestas semidecíduas (Morellato 1992).

Apesar da presença de elementos de florestas estacionais semidecíduas em Itapevi, é nítida a

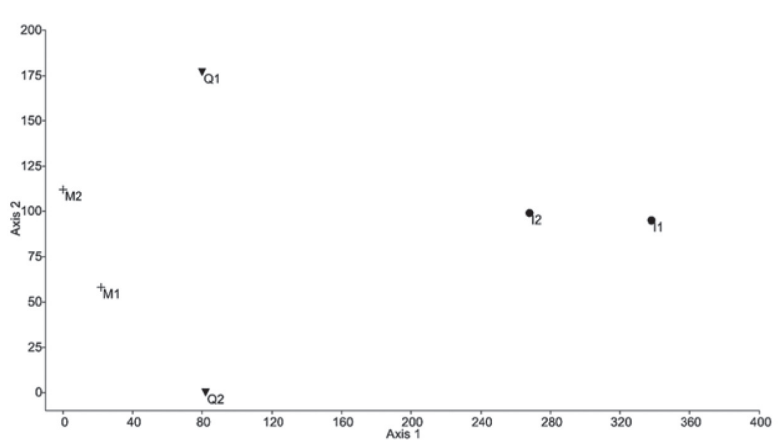

Figura 18. Eixos 1 e 2 da Análise de Correspondência Distendida (DCA) entre as 6 parcelas $(20 \times 50 \mathrm{~m})$ amostradas em três florestas atlânticas maduras da região metropolitana de São Paulo (SP, Brasil), realizada com dados de densidade das espécies. M1 e M2: Marsilac, São Paulo; Q1 e Q2: Reserva Florestal do Morro Grande, Cotia; I1 e 12: Itapevi.

Figure 18. Axis 1 and 2 of the Detrended Correspondence Analysis (DCA) between the six plots $(20 \times 50 \mathrm{~m})$ sampled in three mature Atlantic Forests from São Paulo metropolitan area (São Paulo State, Brazil), using species density data. M1 and M2: Marsilac, São Paulo; Q1 and Q2: Morro Grande Forest Reserve, Cotia; I1 and I2: Itapevi. predominância de espécies típicas das florestas ombrófilas, tais como Cupania oblongifolia, Heisteria silvianii, Myrcia tijucensis e Ocotea catharinensis (Oliveira 2006). Outro aspecto é a baixa representatividade de Rutaceae e Fabaceae em Itapevi, famílias bem expressivas nas florestas estacionais semidecíduas (Rozza 1997, Durigan et al. 2000, Fonseca \& Rodrigues 2000, Oliveira 2006); e a ausência de algumas espécies importantes das matas do interior, tais como Astronium graveolens, Balfourodendron riedelianum, Holocalyx balansae, Metrodorea nigra, Trichilia catigua e Trichilia claussenii. Essas características são indicativas de que Itapevi tenha maior afinidade florística com as florestas ombrófilas, apesar da ocorrência de algumas espécies mais associadas às florestas estacionais semidecíduas.

Em relação às florestas do Morro Grande e de Marsilac, a predominância de espécies ombrófilas é ainda mais evidente (Calyptranthes grandifolia, Calyptranthes lucida, Chrysophyllum flexuosum, Euterpe edulis, Myrcengenia myrcioides, Myrcia tijucensis, Ocotea dispersa, Ocotea catharinensis), e praticamente ausentes elementos característicos de florestas estacionais semidecíduas. Cabe mencionar ainda, que foram amostradas Drimys brasiliensis e observados Araucaria angustifolia, Ilex paraguariensis e Podocarpus lambertii, espécies também amostradas por Catharino et al. (2006) no Morro Grande, e típicas

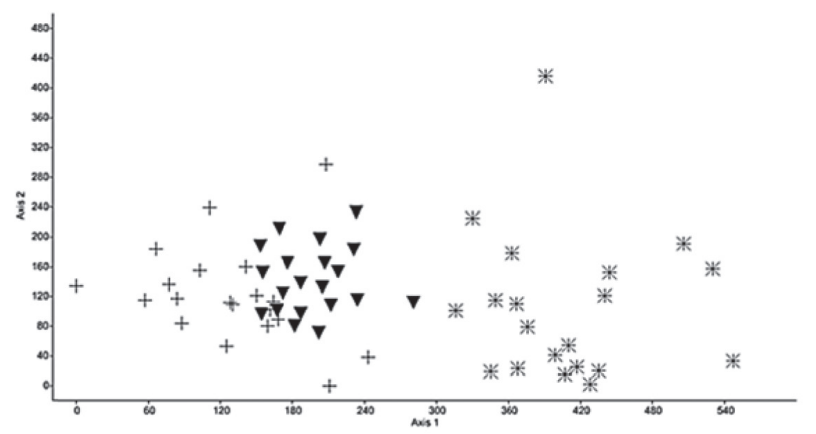

Figura 19. Eixos 1 e 2 da Análise de Correspondência Distendida (DCA) entre as 60 parcelas $(10 \times 10 \mathrm{~m})$ amostradas em três florestas atlânticas maduras da região metropolitana de São Paulo, SP, Brasil, realizada com dados de densidade das espécies. * Itapevi; $\mathbf{\nabla}$ Reserva Florestal do Morro Grande, Cotia; + Marsilac, São Paulo.

Figure 19. Axis 1 and 2 of the Detrended correspondence analysis (DCA) between the sixty plots $(10 \times 10 \mathrm{~m})$ sampled on three mature Atlantic Forests from São Paulo metropolitan area, São Paulo State, Brazil, using species density data. * Itapevi; $\mathbf{\nabla}$ Morro Grande Forest Reserve, Cotia; + Marsilac, São Paulo. 
de climas mais frios e úmidos (Oliveira-Filho \& Fontes 2000). Em trabalho realizado em Ubatuba, Lacerda (2001) relatou que em altitudes de $1.000 \mathrm{~m}$ há um aumento de importância de Lauraceae e Rubiaceae, e as espécies mais típicas dessa comunidade seriam Byrsonima ligustrifolia, Cordiera myrciifolia, Mollinedia $\mathrm{cf}$. boracensis, Myrcengenia myrcioides, Myrciaria tenella, Ocotea divaricata, Ocotea elegans, Posoqueria latifolia e Psychotria suterella, muitas das quais foram amostradas nesse trabalho, indicando que na RMSP também há presença de elementos da flora de florestas mais frias e úmidas. Da mesma forma, a riqueza de lauráceas em Marsilac e Morro Grande também estão de acordo com a denominação "floresta subtropical de Laurales" de Veloso (1966) para as florestas montanas ou submetidas a climas frios e úmidos.

Desse modo, as florestas da RMSP poderiam ser consideradas como predominantemente ombrófilas, mas com elementos de florestas estacionais semidecíduas e também de florestas mistas, frias e úmidas, concordando com outros autores (Aragaki \& Mantovani 1998, Catharino et al. 2006, Durigan et al. 2008). No entanto, este estudo revela uma mudança florística em direção ao interior, aspecto já bem aparente nas parcelas de Itapevi, dentro do complexo cristalino, nos limites do Planalto Paulistano/Planalto de Ibiúna e Serraria de São Roque, corroborando a existência de um gradiente fitogeográfico na região. Dependendo da localização nos planaltos da RMSP, uma mata poderá apresentar maiores ou menores afinidades florísticas com florestas ombrófilas, estacionais, mistas e/ou frio-úmidas, fator que tem desencadeado divergências quanto à classificação mais apropriada para as florestas dessa região do Estado de São Paulo.

Por mais que a discussão sobre a classificação das florestas da RMSP seja importante para o conhecimento científico e para subsidiar políticas de conservação, a maior contribuição desse trabalho é fornecer uma caracterização geral do componente arbóreo de florestas maduras dessa região. É impressionante que a maior região metropolitana do país ainda possua remanescentes quase primitivos de Floresta Atlântica. A importância ecológica dessas poucas manchas de florestas maduras é incalculável. São núcleos de alta diversidade que preservam populações de espécies raras e ameaçadas, as quais fornecem sementes e propágulos que poderiam ser utilizadas para o enriquecimento de florestas secundárias. As composições florística e estrutural dessas matas devem servir de referência para projetos de restauração florestal, os quais deveriam, sempre, buscar atingir as condições e características específicas das florestas primitivas locais. Em relação às florestas da RMSP, parece pouco provável que projetos de restauração estejam utilizando espécies climácicas da região, tais como Cryptocarya saligna, Heisteria silvianii, Micropholis crassipedicellata, Ocotea catharinensis e Pouteria bullata. Projetos mal planejados podem criar florestas com composições florística e estrutural distintas das originais e que, ao longo do tempo, poderiam se misturar com matas nativas e alterar de forma substancial as peculiaridades ecológicas locais.

Por fim, considera-se fundamental haver um esforço em localizar e mapear os escassos núcleos de florestas maduras ainda existentes, juntamente com o direcionamento de pesquisas abordando toda sua biodiversidade, consolidando o conhecimento da biologia das espécies e ecologia dessas comunidades. A falta de estudos em florestas maduras ficou clara com a descoberta de uma espécie nova de Lauraceae, amostrada na Reserva Florestal do Morro Grande (uma árvore com cerca de $30 \mathrm{~m}$ de altura) e recoletada com flores em Marsilac, revelando que ainda há muito a conhecer sobre essas matas, mesmo na maior região metropolitana do país e em uma das floras mais conhecidas do Brasil.

\section{Agradecimentos}

À CAPES, pela bolsa de Mestrado concedida ao primeiro Autor; ao $\mathrm{CNPq}$, pelo apoio financeiro ao projeto desenvolvido (Processo 482050/2011-0); ao Programa de Pós-Graduação do Instituto de Botânica de São Paulo; aos proprietários que permitiram o acesso e desenvolvimento desse trabalho, João Batista, José Ergolich, Francisco de Assis e SABESP; à equipe de campo Ricardo Rosário, Yvan Arbex, Carlinhos e Luciano Mirin; aos Herbários PMSP, SPSF e SP; a Secretaria do Verde e Meio Ambiente do Município de São Paulo; aos botânicos que auxiliaram na identificação do material coletado, João Batista Baitello (Lauraceae), Osny Tadeu Aguiar (Myrtaceae), Marcos Sobral (Myrtaceae), Marcelo da Costa Souza (Myrtaceae - Neomitranthes) e Inês Cordeiro (Euphorbiaceae e Phyllantaceae).

\section{Literatura citada}

APG III. 2009. An update of the Angiosperm Phylogeny Group classification for the orders and families of flowering plants: APG III. Botanical Journal of the Linnean Society 16: 105-121. 
Aragaki, S. 1997. Florística e estrutura de trecho remanescente de floresta no Planalto Paulistano (SP). Dissertação de Mestrado, Universidade de São Paulo, São Paulo, SP.

Aragaki, S. \& Mantovani, W. 1998. Caracterização do clima e da vegetação de remanescente florestal no planalto paulistano (SP). In: Anais do IV Simpósio de Ecossistemas Brasileiros, Aciesp 104, pp. 25-36.

Arzolla, F.A.R.D.P. 2002. Florística e fitossociologia de trecho da Serra da Cantareira, Núcleo Águas Claras, Parque Estadual da Cantareira, Mairiporã, SP. Dissertação de Mestrado, Universidade Estadual de Campinas, Campinas, SP.

Arzolla, F.A.R.D.P. 2011. Florestas secundárias e a regeneração natural de clareiras antrópicas na Serra da Cantareira, SP. Tese de Doutorado, Universidade Estadual de Campinas, Campinas, SP.

Arzolla, F.A.R.D.P., Vilela, F.E.S.P., Paula, G.C.R., Shepherd, G.J., Descio, F. \& Moura, C. 2011. Composição florística e a conservação de florestas secundárias na Serra da Cantareira, São Paulo, Brasil. Revista do Instituto Florestal 23: 149-171.

Baitello, J.B, Aguiar, O.T., Rocha, F.T, Pastore, J.A. \& Esteves, R. 1993. Estrutura fitossociológica da vegetação arbórea da Serra da Cantareira (SP) - Núcleo Pinheirinho. Revista do Instituto Florestal 5: 133-161.

Bernacci, L.C., Franco, G.A.D.C., Arbocz, G.F., Catharino, E.L.M., Durigan, G. \& Metzger, J.P. 2006. O efeito da fragmentação florestal na composição e riqueza de árvores na região da Reserva Florestal do Morro Grande (Planalto de Ibiúna, SP). Revista do Instituto Florestal 18: 121-166.

BRASIL. 2006. Lei Federal n. 11.428, de 22-XII-2006. Dispõe sobre a utilização e proteção da vegetação nativa do Bioma Mata Atlântica, e dá outras providências. Diário Oficial da União, Brasília, 26-XII-2006. Seção 1, n. 246, pp. 1-4.

Budowski, G. 1963. Forest sucession in tropical lowlands. Turrialba 13: 42-44.

Budowski, G. 1965. Distribution of tropical American rainforest species in the light of successional processes. Turrialba 15: 41-42.

Budowski, G. 1970. The distinction between old secondary and climax species in tropical Central American lowlands forests. Tropical Ecology 11: 44-48.

Cardoso-Leite, E. 1995. Ecologia de um fragmento florestal em São Roque, SP: florística, fitossociologia e silvigênese. Dissertação de Mestrado, Universidade Estadual de Campinas, Campinas, SP.

Catharino, E.L.M. \& Aragaki, S. 2008. A vegetação do município de São Paulo: de Piratininga à metrópole paulistana. In: Malagoli, L. R., Bajesteiro, F. B. \& Whately, M. (orgs.). Além do concreto: contribuições para a proteção da biodiversidade paulistana. São Paulo: Instituto Socioambiental, pp. 54-91.
Catharino, E.L.M. 1989. Estudos fisinômicos-florísticos e fitossociológicos em matas residuais secundárias no município de Piracicaba, SP. Dissertação de Mestrado, Universidade Estadual de Campinas, Campinas (SP).

Catharino, E.L.M. 2006. As Florestas Montanas da Reserva Florestal do Morro Grande, Cotia (SP). Tese de Doutorado, Universidade Estadual de Campinas, Campinas, SP.

Catharino, E.L.M., Bernacci, L.C., Franco, G.A.D.C., Durigan, G. \& Metzger, J.P.W. 2006. Aspectos da composição e diversidade do componente arbóreo das florestas da Reserva Florestal do Morro Grande, Cotia, SP. Biota Neotropica 6: 1-28.

Colwell, R.K. 2013. EstimateS: Statistical estimation of species richness and shared species from samples. Version 9.

Conselho Nacional do Meio Ambiente. 1994. Resolução CONAMA-01, de 31-I-1994. Regulamenta o Decreto n. 750 , de 10 de fevereiro de 1993 e a Resolução CONAMA $n^{\circ} 10$ de $1^{\circ}$ de outubro de 1993 em relação à necessidade de se definir vegetação primária e secundária nos estágios pioneiro, inicial, médio e avançado de regeneração de Mata Atlântica a fim de orientar os procedimentos de licenciamento de exploração nativa do Estado de São Paulo. Diário Oficial da União, Brasília, 03-II-1994. Seção 1, n. 24, pp. 79-80.

Dislich, R., Cersósimo, L. \& Mantovani, W. 2001. Análise da estrutura de fragmentos florestais no Planalto Paulistano SP. Revista Brasileira de Botânica 24: 321-332.

Durigan, G., Bernacci, L.C., Franco, G.A.D.C., Arbocz, G.F., Metzger, J.P. \& Catharino, E.L.M. 2008. Estádio sucessional e fatores geográficos como determinantes da similaridade florística entre comunidades florestais no Planalto Atlântico, Estado de São Paulo, Brasil. Acta Botânica Brasílica 22: 51-62.

Durigan, G., Franco, G.A.D.C., Saito, M. \& Baitello, J.B. 2000. Estrutura e diversidade do componente arbóreo da floresta na Estação Ecológica dos Caetetus, Gália, SP. Revista Brasileira de Botânica 23: 369-381.

EMBRAPA. 2003. Banco de dados climáticos do Brasil. Disponível em http://www.bdclima.cnpm.embrapa.br/ resultados/index.php?UF=sp (acesso em 15-I-2013).

Fidalgo, O. \& Bononi, V.L.R. (coord.). 1984. Técnicas de coleta, preservação e herborização de material botânico. São Paulo. Instituto de Botânica, Manual 4.

Fonseca, R.C.B. \& Rodrigues, R.R. 2000. Análise estrutural e aspectos do mosaico sucessional de uma floresta semidecídua em Botucatu, SP. Scientia Forestalis 57: 27- 43.

Forzza, R.C., Stehmann, J.R \& Nadruz, M. (coord). 2013. Lista de Espécies da Flora do Brasil 2013. Disponível em http://floradobrasil.jbrj.gov.br/ (acesso em 5-XII-2013).

Gandolfi, S. 1991. Estudo florístico e fitossociológico de uma floresta residual na área do Aeroporto Internacional de São Paulo, Guarulhos, SP. Dissertação de mestrado, Universidade Estadual de Campinas, Campinas, SP. 
Gandolfi, S. 2000. História natural de uma floresta estacional semidecidual no município de Campinas (São Paulo, Brasil). Tese de doutorado, Universidade Estadual de Campinas, Campinas, SP.

Gandolfi, S., Leitão-Filho, H.F. \& Bezerra, C.L. 1995. Levantamento florístico e caráter sucessional das espécies arbustivo-arbóreas de uma floresta mesófila semidecídua no Município de Guarulhos, SP. Revista Brasileira de Biologia 55: 753-767.

Garcia, R.J.F. \& Pirani, J.R. 2001. Estudo florístico dos componentes arbóreo e arbustivo da mata do Parque Santo Dias, São Paulo, SP, Brasil. Boletim da Universidade de São Paulo 19: 15- 42.

Gomes, E.P.C. 1992. Fitossociologia do componente arbóreo de um trecho de mata em São Paulo, SP. Dissertação de mestrado. Instituto de Biociências, Universidade de São Paulo, São Paulo, SP.

Gorenstein, M.R. 2002. Métodos de amostragem no levantamento da comunidade arbórea em Floresta Estacional Semidecidual. Dissertação de Mestrado. Universidade de São Paulo, Piracicaba, SP.

Grombone, M.T., Bernacci, L.C., Meira Neto, J.A.A., Tamashiro, J.Y. \& Leitão-Filho, H.F. 1990. Estrutura fitossociológica de uma floresta semidecídua de altitude do Parque Estadual de Grota Funda (Atibaia, SP). Acta Botanica Brasilica 4: 47-64.

Guapyassú, M.S. 1994. Caracterização fitossociológica de três fases sucessionais de uma floresta ombrófila densa sub-montana, Morretes, PR. Dissertação de mestrado, Universidade Federal do Paraná, Curitiba, PR.

Guariguata, M.R. \& Ostertag, R. 2001. Neotropical secondary forest succession: changes in structural and functional characteristics. Forest Ecology and Management 148: 185-206.

Hammer, O., Harper, D.A.T. \& Ryan, P.D. 2001.PAST Paleontological Statistics software package for education and data analysis. Palaeontologia Electronica 4: 9.

Harlshorn, G.S. 1980. Neotropical Forest Dynamics. Biotropica 12: 23-30.

Hill, M.O.\& Gauch, H.G. 1980. Detrended Correspondence analysis: an improved ordination technique. Vegetation 42: 47-58.

Ministério do Meio Ambiente 2008. Instrução Normativa MMA n. 06, de 23-IX-2008. Lista Oficial de Espécies da Flora Brasileira Ameaçada de Extinção. Diário Oficial da União, Brasília, 24-IX-2008. Seção 1, n. 185, pp. 75-83.

IBGE. 2004. Mapa da vegetação do Brasil. 3 ed. Rio de Janeiro, RJ.

IBGE. 2012. Manual técnico da Vegetação Brasileira. Rio de Janeiro, RJ.

IUCN. 2013. IUCN Red List of Threatened Species. Version 201. Disponível em http://www.redlist.org (acesso em 15-V-2013).

Koppen, W. 1948. Climatologia. Mexico: Fondo Cultura Economia.
Lacerda, M.S. 2001. Composição florística e estrutura da comunidade arbórea num gradiente altitudinal da Mata Atlântica. Tese de doutorado, Universidade Estadual de Campinas, Campinas, SP.

Leitão-Filho, H.F. (org.). 1993. Ecologia da Mata Atlântica em Cubatão. Editora UNESP/Editora UNICAMP, Campinas, SP.

Leitão-Filho, H.F. 1982. Aspectos taxonômicos das florestas do Estado de São Paulo. Silvicultura em São Paulo 16(A): 197-206.

Lima, L.R. \& Pirani, J.R. 2005. Burseraceae. In: M.G.L. Wanderley, G.J. Shepherd, T.S. Melhem \& A.M. Giulietti (coords.). Flora Fanerogâmica do Estado de São Paulo, vol. 4. FAPESP \& Rima, São Paulo, SP.

Loefgren, A. 1896. Ensaio para uma distribuição dos vegetaes nos diversos grupos florísticos no Estado de São Paulo. Boletim da Commissão Geographica e Geologica de São Paulo 11: 5-50.

Loureiro, M.A.S. 1981. A evolução da casa paulistana e a arquitetura de Ramos de Azevedo. Voz do Oeste, Secretaria de Estado da Cultura, São Paulo, SP.

Martinelli, G. \& Moraes, M.A. (orgs.). 2013. Livro Vermelho da Flora do Brasil. Instituto de Pesquisas Jardim Botânico do Rio de Janeiro, RJ.

McCune, B. \& Mefford, M. J. 2011. PC-ORD. Multivariate analysis of Ecological Data, Version 6.0.

Morellato, L.P.C. 1992. Padrões de frutificação e dispersão na Serra do Japi. In: Morellato, L.P. (org.). Ecologia e preservação de uma área florestal no Sudeste do Brasil. Editora da Unicamp, Campinas, SP, pp.112-140.

Mueller-dombois, D. \& Ellemberg, H. 1974. Aims and methods of vegetation ecology. New York, Jonh Willey $\&$ Sons.

Ogata, H. \& Gomes, E.P.C. 2006. Estrutura e composição da vegetação no Parque CEMUCAM, Cotia, SP. Hoehnea 33: 371-384.

Oksanen, J. 2011. Multivariate analysis of ecological communities in R: vegan tutorial. Disponível em: http://cc.oulu.fi/ jarioksa/opetus/metodi/vegantutor.pdf (acesso em 15-I-2015).

Oliveira, J.B., Camargo, M.N., Rossi, M. \& Calderanofilho, B. 1999. Mapa Pedológico do Estado de São Paulo. Ministério da Agricultura e do Abastecimento, Empresa Brasileira de Pesquisa Agropecuária, Instituto Agronômico de Campinas \& Governo do Estado de São Paulo.

Oliveira, R.J. 2006. Variação da composição florística e da diversidade alfa das florestas atlânticas no estado de São Paulo. Tese de doutorado, Universidade Estadual de Campinas, Campinas, SP.

Oliveira-filho, A.T. \& Fontes, M.A.L. 2000. Patterns of floristic differentiation among Atlantic Forests in southeastern Brazil and the influence of climate. Biotropica 32(4b): 793-810. 
Pielou, E. C. 1975. Ecological diversity. New York: Wiley.

Pijl, L. van der. 1982. Principles of dispersal in highter plants. Springer-Verlag, Berlim.

Reitz, R.; Klein, R.M. \& Reis, A. 1979. Madeiras do Brasil. Lunardelli, Florianópolis, SC.

Rodrigues, R.R. 1986. Levantamento florístico e fitossociológico das matas da Serra do Japi, Jundiaí, SP. Dissertação de mestrado. Universidade Estadual de Campinas, Campinas, SP.

Roizman, L.G. 1993. Fitossociologia e dinâmica do banco de sementes de populações arbóreas de uma floresta secundária em São Paulo. Dissertação de mestrado, Universidade de São Paulo, São Paulo, SP.

Rosário, R.P.G. 2010. Estágios sucessionais e o enquadramento jurídico das florestas montanas secundárias na Reserva Florestal do Morro Grande (Cotia, SP) e entorno. Dissertação de Mestrado, Instituto de Botânica da Secretaria de Estado do Meio Ambiente, São Paulo, SP.

Rozza, A.F. 1997. Florística, fitossociologia e caracterização sucessional de uma floresta estacional semidecidual, Mata da Virgínia, Matão, SP. Dissertação de mestrado, Universidade Estadual de Campinas, Campinas, SP.

Salis, S.M., Shepherd, G.J. \& Joly, C.A. 1995. Floristic comparison of mesophytic semideciduous forests of interior of the state of São Paulo, Southeast Brazil. Vegetatio 119: 155-164.

Setzer, J. 1966. Atlas climático e ecológico do Estado de São Paulo. Comissão Interestadual da bacia do Paraná e Centrais Elétricas de São Paulo, São Paulo, SP.

Shepherd, G.J. 2010. Fitopac. Versão 2.1.2.85. Universidade Estadual de Campinas, Campinas, SP.

Silveira, D.S. 2009. Revisão taxonômica das espécies neotropicais extra-amazônicas de Sloanea L. Tese de doutorado. Universidade Estadual de Campinas, Campinas, SP.
Secretaria do Meio Ambiente do Estado de São Paulo. 2004. Resolução SMA-48, de 21-IX-2004 Lista oficial das espécies da flora do Estado de São Paulo ameaçadas de extinção. Diário Oficial do Estado de São Paulo, Poder Executivo, São Paulo, 22-IX-2004. Seção I, v. 114, n. 179, pp. 26-29.

Thornthwaite, C.W \& Mather, J.R. 1955. The water balance. Publications in Climatology. New Jersey: Drexel Institute of Technology.

Tomasulo, P.L.B. 1995. Análise da composição florística e estrutura da vegetação como subsídio ao plano de manejo para o Parque Municipal da Serra do Itapety, Mogi das Cruzes, SP. Dissertação de mestrado, Universidade Federal de Minas Gerais, Belo Horizonte, MG.

Valentim, J.L. 2000. Ecologia Numérica: uma introdução à análise multivariada de dados ecológicos. Interciência, Rio de Janeiro, RJ.

Vasconcellos, R. \& Tarifa, J.R. 1982. Estimativa e representação das temperaturas no Brasil: uma análise geográfica. Revista do Departamento de Geografia, Universidade de São Paulo, São Paulo, SP.

Veloso, H.P. \& Góes-Filho, L. 1982. Fitogeografia Brasileira Classificação Fisionômico-Ecológica da Vegetação Neotropical. Boletim Técnico Radam-Brasil série Vegetação 1:1-80.

Veloso, H.P. 1966. Atlas Florestal do Brasil. Ministério da Agricultura, Serviço de Informação Agrícola, Rio de Janeiro, RJ.

Vuono, Y. 1985. Fitossociologia do estrato arbóreo da floresta da reserva biológica do Instituto de Botânica (São Paulo, SP). Tese de Doutorado, Universidade de São Paulo, SP. 